\title{
Sociedad, participación política y Estado en China e India: la relevancia del capital social
}

\author{
State, Society and Political \\ Participation in China and India: \\ The Relevance of the Social Capital
}

\author{
FRANCISCO JAVIER HARO NAVEJAS* \\ CRISTINA TAPIA MURO*
}

Resumen: En China e India, los factores contextuales e individuales influyen en la probabilidad de participar en política de diferentes formas. Este ensayo centra la atención en el papel que desempeñan los diversos tipos de capital social. Con ese objetivo se estudian datos provenientes de la Encuesta Mundial de Valores (World Values Survey) sobre estos países. Para identificar los factores alentadores de la participación política, algunas investigaciones se han enfocado en el capital social; no obstante, son relativamente pocos los trabajos que abordan el tema incluyendo una diferenciación de ambos conceptos. Tradicionalmente, los especialistas han observado la participación política solamente a partir del voto, mientras que el capital social lo analizan sin atender al tipo del cual se trate.

Palabras clave: participación política; capital social; China; India.

Abstract: In this paper, we provide evidence of certain factors that, in China and India, trigger political participation. Supported by data from the World Values Survey, our analysis focuses on the role of different types of social capital. With this approach, we analyze both

Recepción: 11 de agosto de 2016. / Aceptación: 4 de octubre de 2016.

*Universidad de Colima, fharo@ucol.mx y ctapia@ucol.mx 
contextual and individual factors. Our approach is based on the fact that, even when experts have researched the role of social capital, relatively few of them have differentiated between contextual and individual factors. Traditionally, scholars have analyzed political participation in such a way that voting is the only important factor; also, they have not paid attention to different types of social capital.

Key words: political participation; social capital; China; India.

\section{Introducción}

¿Qué factores inciden en la probabilidad de que un ciudadano participe políticamente? Al intentar responder esta pregunta, Brady, Verba y Schlozman ${ }^{1}$ señalan que las razones por las que no participa se agrupan en torno a tres causas: "porque no pueden, porque no quieren o porque nadie los invitó”. Los recursos disponibles, el interés en el tema y el acceso a redes y espacios a través de los cuales ocurre la movilización política explican su intervención en ella. Diversos especialistas, enfocándose tradicionalmente en el voto, han tomado como base dichos factores para establecer los elementos que determinan una sociedad políticamente activa en los diferentes países. Otros autores, ${ }^{2}$ sin embargo, destacan la necesidad de atender a distintas manifestaciones políticas.

Especialistas como Arriagada reconocen diversos tipos de capital social según el criterio a partir del cual se clasifique. ${ }^{3}$ Debido a la heterogeneidad en redes y a las interacciones que surgen de éstas, resulta importante e interesante observar sus efectos en la participación política de manera diferenciada. ${ }^{4}$

${ }^{1}$ H. Brady, S. Verba y K. Schlozman, "Beyond ses: A Resource Model of Political Participation", The American Political Science Review, vol. 89, núm. 2, 1995, p. 271.

${ }^{2}$ Estudios como los de Rosenstone y Hansen; Verba, Nie y Kim; citados en A. Krishna, "Enhancing Political Participation in Democracies: What is the Role of Social Capital?”, Comparative Political Studies, vol. 35, núm. 4, 2002, p. 438.

${ }^{3}$ I. Arriagada, Breve guía para la aplicación del enfoque de capital social en los programas de pobreza, Santiago de Chile, Comisión Económica para América Latina y el Caribe, 2006.

${ }^{4}$ K. Ikeda y S. Richey, "Japanese Network Capital: The Impact of Social Networks on Japanese Political Participation”, Political Behavior, vol. 27, núm. 3, 2005, pp. 239-260. 
En el caso de China se asume a priori poca participación de los ciudadanos. La presunción parte de la constatación superficial del carácter piramidal del iceberg que representa el sistema político chino. De acuerdo con esta percepción, el conjunto de las decisiones políticas las toma, a final de cuentas, una persona. En el vértice superior un hombre es, al mismo tiempo, secretario general del Partido Comunista, presidente de la República y cabeza de las comisiones centrales militares, la del Estado y la del partido. La fuerza relativa del personaje, actualmente $\mathrm{Xi}$ Jinping, es indiscutible, al igual que sus intenciones de acumular poder. No obstante el proceso histórico y la legitimidad de ese tipo de liderazgo en China, es posible apreciar diferentes manifestaciones sustanciales de participación política de fuerzas no totalmente controladas por el principal personaje político del sistema, y esto gracias a la complejidad de la relación entre el Estado y la sociedad civil, así como a la que se da dentro de las propias fuerzas estatales.

En India, a su vez, la atención académica se ha centrado tradicionalmente en la dimensión electoral, y a partir de ésta se le ha considerado la democracia más grande del mundo. El adjetivo, esencialmente cuantitativo, invisibiliza y descalifica otras formas de participación tanto en el continente del sur de Asia como en otras partes del mundo. Algunos autores han externado la idea de que la única forma de participación política es el voto, lo que genera la percepción de que donde no se vota, o se vota poco, la sociedad no interviene en la política.

Analizar los casos de China e India en este marco resulta, pues, relevante por diversas razones, entre las que destaca la disparidad entre las élites de ambos gigantes económicos sobre el tema del desarrollo y la relación entre éste y las características de los sistemas políticos. ${ }^{5}$ Comprender lo anterior implica identificar los alcances y la naturaleza de la cultura política en cada uno de los casos, tarea a la que abona este estudio mediante el contraste del efecto del capital social sobre diferentes tipos de participación política en dos países con regímenes distintos, pero que han compartido algunos componentes en determinados

${ }^{5}$ J. Drèze y A. Sen, Una gloria incierta: India y sus contradicciones, Madrid, Taurus, 2014, pp. 27 y 30. 
momentos de su historia, como el peso del partido dominante, el gobierno dentro de cierto multipartidismo -más funcional en India que en China, donde ha sido esencialmente simbólico-, y el peso del Estado como instrumento para el crecimiento económico, así como para el impulso de grupos beneficiados $\mathrm{y}$ alentadores del mismo.

¿De qué modo las redes personales y la confianza influyen en la actividad política? ¿Es posible hablar de un efecto directo independientemente de las instituciones que dan forma a la vida política del Estado en cuestión?

En este trabajo avanzamos en la identificación de los aspectos que afectan las diferentes formas de participación política, con especial atención al papel del capital social porque constituye un espacio movilizador que, presumiblemente, concentra a personas con perfiles o prioridades similares en cuanto a características no observables, como el interés en el desarrollo, ya sea personal o comunitario. Nuestro sustento conceptual es que el capital social influye positiva y diferenciadamente ${ }^{6}$ en las formas de participación política. ${ }^{7}$ Para verificarlo, proponemos una clasificación del capital social basada en la información estadística disponible; nuestra idea central es que la pertenencia a determinados tipos de organizaciones o redes señala la motivación para construir este tipo de capital.

Estimamos modelos de variables dependientes binarias, probit, con los últimos datos disponibles de la Encuesta Mundial de Valores (World Values Survey o wvs) para los casos de China e India, mismos que resultan representativos a escala nacional.

El trabajo se dividió en cuatro apartados. En el primero fijamos las bases conceptuales y posteriormente se presenta la revisión de la literatura. Después se muestran las variables cons-

${ }^{6}$ R. Putnam, Making Democracy Work. Civic Traditions in Modern Italy, Princeton, Princeton University Press, 1993; J. Klesner, "Social Capital and Political Participation in Latin America. Evidence from Argentina, Chile, Mexico, and Peru", Latin American Research Review, vol. 42, núm. 2, 2007, pp. 1-32, y J. Klesner, "Who Participates? Determinants of Political Action in Mexico", Latin American Politics and Society, vol. 51, núm. 2, 2009, pp. 59-90.

7 A. Lee, "The Quality of Social Capital and Political Participation in South Korea”, Journal of East Asian Studies, vol. 10, 2010, pp. 483-505, y C. Teney y L. Hanquinet, "High Political Participation, High Social Capital? A Relational Analysis of Youth Social Capital and Political Participation”, Social Science Research, vol. 41, núm. 5, 2012, pp. 1213-1226. 
truidas y la metodología empleada. En el cuarto apartado damos cuenta del análisis realizado y de los principales hallazgos del texto; se destacan los perfiles de los habitantes políticamente activos, así como las principales formas de las que éstos se valen para incidir en el sector público de los países estudiados.

\section{Bases conceptuales}

La participación política, en una definición ya clásica, se refiere a "los actos legales de ciudadanos privados que están más o menos encaminados a influir sobre la selección del personal gubernamental o las acciones que ellos toman". ${ }^{8}$ Posteriormente, Brady enfatizó tres elementos de la participación: las acciones específicas y voluntarias en las cuales las personas se incluyen, la calidad de "ciudadanos ordinarios" de los participantes - lo que excluye a políticos- y la intención deliberada de influir en asuntos públicos. ${ }^{9}$ A partir de esto, diferentes especialistas han elaborado tipologías de la participación. Teorell, Torcal y Montero se remiten a las dimensiones identificadas por Verba y sus colegas como base para su clasificación, y reconocen así la participación electoral, la del consumidor, la actividad partidista, la de protesta y la de contacto. ${ }^{10}$

Para fines de esta investigación, la participación política se entiende como toda acción voluntaria realizada por ciudadanos ordinarios dirigida a influir en el sector público. En esta definición se incluyen, además del voto, otras acciones que tienen cabida en la clasificación de Teorell, como la membresía a partidos políticos, firma de peticiones, y asistencia a boicots, manifestaciones y otras demostraciones pacíficas. Cabe destacar que, entre las mencionadas, es posible distinguir las identificadas como acción política convencional (voto, pertenencia a par-

${ }^{8}$ S. Verba, N. Nie y J. Kim, Participation and Political Equality: A Seven-Nation Comparison, Cambridge-Nueva York, Cambridge University Press, 1978, p. 46.

${ }_{9}^{9}$ Citado en J. Ekman y E. Amna, "Political Participation and Civic Engagement: Towards a New Typology”, Human Affairs, vol. 22, núm. 3, 2012, p. 286.

${ }^{10} \mathrm{~J}$. Teorell, M. Torcal y J. Montero, "Political Participation: Mapping the Terrain”, en J. van Deth, J. Montero y A. Westholm (eds.), Citizenship and Involvement in European Democracies: A Comparative Analysis, Londres, Routledge, 2007, pp. 341 y 343 . 
tidos políticos) y no convencional (boicots, manifestaciones) según la aportación de Rucht. ${ }^{11}$

En cuanto al capital social, es posible distinguir diferentes enfoques según la disciplina a la que corresponden: sociología, economía y ciencia política. ${ }^{12}$ Respecto a esta última, probablemente el trabajo más emblemático corresponde a Putnam, quien conceptualiza el capital social como el conjunto de "características de la organización social, como confianza, normas y redes, que pueden mejorar la eficiencia de la sociedad facilitando acciones coordinadas". ${ }^{13}$

Pese a la gran diversidad de enfoques del tema, hay dos elementos comunes: la importancia de la asociación entre los actores y su efecto, con miras a facilitar acciones de diferente índole. Puede decirse que la función o efecto resultante de la pertenencia a una red es en sí mismo el capital o "activo" social del individuo ${ }^{14}$ (cuadro 1).

En esta investigación, además, entendemos por capital social el "activo social" con que cuenta el individuo como resultado de sus interacciones sociales y los recursos acumulados a partir de sus relaciones con personas que tienden al logro de objetivos afines. Esta postura parte de la idea de Lin, quien, de acuerdo con Millán y Gordon, entiende el capital social "como un activo social generado por las conexiones entre actores y constituido por recursos de los que se carece, que otros poseen $\mathrm{y}$ a los que se puede acceder porque quien los posee desea ejercer influencia". ${ }^{15}$ Nuestra hipótesis es que ciertas interacciones de la persona (tipos de capital social específico), además de potenciar los esfuerzos individuales en áreas determinadas, se convierten en el vehículo o incentivo de otras conductas personales, como algunas formas de participación política.

Clasificamos el capital social en atención a la información disponible y tomando como punto de partida el grado de

${ }^{11}$ J. S. Fernández y A. J. Rojas, "Escala de acción política no convencional. Análisis de fiabilidad y validez", Psicología Política, núm. 26, 2003, p. 42.

${ }_{12}$ A. Portes, "Social Capital: Its Origins and Applications in Modern Sociology", Annual Review of Sociology, vol. 24, 1998, pp. 1-24.

${ }_{13}$ Putnam, Making Democracy Work..., op. cit., p. 167.

${ }^{14}$ Arriagada, Breve guía..., op. cit., p. 7.

${ }^{15}$ R. Millán y S. Gordon, "Capital social: una lectura de tres perspectivas clásicas”, Revista Mexicana de Sociología, núm. 4, 2004, p. 739. 


\section{Cuadro 1. Definiciones de capital social. Énfasis y beneficios según autor}

\begin{tabular}{|c|c|c|}
\hline Autor & Énfasis & Beneficios \\
\hline $\begin{array}{l}\text { Robert } \\
\text { Putnam }\end{array}$ & $\begin{array}{l}\text { Asociacionismo } \\
\text { horizontal }\end{array}$ & $\begin{array}{l}\text { Redes sociales y normas que afectan } \\
\text { la productividad de la comunidad }\end{array}$ \\
\hline $\begin{array}{l}\text { James } \\
\text { Coleman }\end{array}$ & $\begin{array}{l}\text { Asociaciones } \\
\text { horizontales y verticales }\end{array}$ & $\begin{array}{l}\text { Constituye un activo de capital } \\
\text { para individuos y facilita sus acciones }\end{array}$ \\
\hline $\begin{array}{l}\text { Francis } \\
\text { Fukuyama }\end{array}$ & $\begin{array}{l}\text { Recursos morales y } \\
\text { mecanismos culturales }\end{array}$ & $\begin{array}{l}\text { Sociedad civil saludable y buen } \\
\text { funcionamiento institucional }\end{array}$ \\
\hline $\begin{array}{l}\text { Douglas } \\
\text { North } \\
\text { Marcus } \\
\text { Olson }\end{array}$ & $\begin{array}{l}\text { Neoinstitucionalismo } \\
\text { económico (relaciones } \\
\text { formales e informales, } \\
\text { horizontales y jerárquicas } \\
\text { institucionalizadas, } \\
\text { estructuras de gobierno, } \\
\text { régimen político, Estado } \\
\text { de derecho, sistema } \\
\text { judicial y libertades } \\
\text { civiles y políticas) }\end{array}$ & $\begin{array}{l}\text { Reduce costos de transacción } \\
\text { Produce bienes públicos } \\
\text { Organización de base efectiva }\end{array}$ \\
\hline \multirow{3}{*}{$\begin{array}{l}\text { John } \\
\text { Durston }\end{array}$} & \multirow{3}{*}{$\begin{array}{l}\text { Confianza, cooperación } \\
\text { y reciprocidad }\end{array}$} & $\begin{array}{l}\text { Capital social individual } \\
\text { (redes egocentradas) }\end{array}$ \\
\hline & & $\begin{array}{l}\text { Capital social grupal } \\
\text { (grupos o redes de apoyo en el ámbito } \\
\text { productivo y extraproductivo) }\end{array}$ \\
\hline & & $\begin{array}{l}\text { Capital social comunitario } \\
\text { (institucionalidad local con capacidad } \\
\text { de autogestión) }\end{array}$ \\
\hline \multirow{3}{*}{$\begin{array}{l}\text { Pierre } \\
\text { Bourdieu }\end{array}$} & $\begin{array}{l}\text { Recursos reales o } \\
\text { potenciales de una red } \\
\text { durable de relaciones }\end{array}$ & $\begin{array}{l}\text { Permite la movilidad social de agentes } \\
\text { en la estructura social. Rol del conflicto. } \\
\text { Explicita relaciones de poder desiguales }\end{array}$ \\
\hline & $\begin{array}{l}\text { Instituciones, relaciones, } \\
\text { actitudes, valores }\end{array}$ & $\begin{array}{l}\text { Desarrollo económico } \\
\text { Democracia }\end{array}$ \\
\hline & Capital social de unión & $\begin{array}{l}\text { Lazos próximos (redes que se configuran } \\
\text { a partir de los lazos de familia, de amistad } \\
\text { cercana y de comunidad) }\end{array}$ \\
\hline \multirow[b]{2}{*}{$\begin{array}{l}\text { Banco } \\
\text { Mundial }\end{array}$} & Capital social de puente & $\begin{array}{l}\text { Nexos entre personas y grupos similares, } \\
\text { pero en distintas ubicaciones geográficas }\end{array}$ \\
\hline & Capital social de escalera & $\begin{array}{l}\text { Lazos que generan sinergia entre } \\
\text { grupos disímiles. Abre oportunidades } \\
\text { económicas a aquellos que pertenecen a } \\
\text { los grupos menos poderosos o excluidos }\end{array}$ \\
\hline
\end{tabular}

Fuente: I. Arriagada, Breve guía para la aplicación del enfoque de capital social en los programas de pobreza, Santiago de Chile, Comisión Económica para América Latina y el Caribe, 2006, pp. 9-10. 
agregación de los réditos que el individuo espera alcanzar a través de su pertenencia a distintas organizaciones; entendemos que esto es una señalización del tipo de motivación que tiene el sujeto para incluirse en estas células. Este tipo de diferenciación está orientado por el supuesto de que los individuos cuya preocupación por el bienestar común se manifiesta al punto de pertenecer a una asociación con este tipo de fines serán más proclives a participar de diferentes formas en temas políticos, debido a las repercusiones sociales que tienen. En contraste, la probabilidad de participar activamente en política será menor en los electores cuyos vínculos están construidos a partir de una lógica de bienestar personal más que grupal.

A partir del concepto y la clasificación expuestos, identificamos tres tipos de capital social:

1. Para el desarrollo individual (CSDI). Membresías cuyo efecto o función es facilitar a los individuos acciones tendientes al desarrollo personal.

2. Para el desarrollo grupal o comunitario (CSDC). Pertenencia a grupos cuyo efecto o función es facilitar acciones encaminadas al desarrollo de un conjunto de personas, independientemente de su magnitud.

3. Bivalente (CSB). Inclusión en grupos cuya finalidad se materializa en acceso al desarrollo en uno u otro de los dos planos anteriores (individual o grupal), según sea el caso.

Pese a la similitud entre la nomenclatura de esta clasificación y la de Durston, este último se refiere al nivel al cual se genera el capital social. Es decir, por capital social individual concibe "el crédito que ha acumulado la persona en la forma de reciprocidad difusa que puede reclamar en momentos de necesidad [...] Este recurso reside no en la persona misma, sino en las relaciones entre las personas". Mientras que por capital social colectivo o comunitario se entiende aquel que "consta de las normas y estructuras que conforman las instituciones de cooperación grupal". ${ }^{16}$

${ }^{16} \mathrm{~J}$. Durston, ¿Quées capital social comunitario?, Serie Políticas Sociales, núm. 38, Santiago de Chile, Comisión Económica para América Latina y el Caribe, 2000, p. 21. 


\section{Participación social y capital social en la academia}

La participación política constituye un fenómeno ampliamente estudiado. Newton reconoce dos vertientes teóricas para explicar el apoyo político: una centrada en el desempeño económico y político de los gobiernos, y otra más vinculada al capital social. ${ }^{17}$

Krishna, a su vez, tomando como criterio la interacción, señala tres vertientes en la investigación de la participación política: nivel micro, macro y meso. ${ }^{18}$ Entre los autores que abordan el nivel micro, destacan Almond y Verba, Bennett y Bennett, $y$ Lipset, Rosenstone y Hansen. Autores como Jackman y Miller, Joseph y Linz y Stepan se han centrado en el nivel macro. ${ }^{19} \mathrm{El}$ nivel meso ha sido estudiado por académicos como Brown y Brown, ${ }^{20}$ quienes explican el activismo político a partir de capital social de base religiosa; Nickerson ${ }^{21}$ y Condon, ${ }^{22}$ que plantean el tema a partir de métodos experimentales; y Klesner, ${ }^{23}$ y Teney y Hanquinet, ${ }^{24}$ que además de tocar el vínculo de la participación política con el capital social, agregan variables de índole individual, o de nivel micro, a sus respectivos modelos. En este mismo grupo de trabajos, Ikeda y Richey, ${ }^{25}$ Ikeda, Yamada y Kohno, ${ }^{26}$ y Lee ${ }^{27}$ analizan los casos de Japón y Corea del Sur respectivamente. Sin embargo, estos últimos, a diferencia de

${ }^{17}$ K. Newton, "Political Support: Social Capital, Civil Society and Political and Economic Performance”, Political Studies, vol. 54, 2006, p. 846.

${ }^{18}$ Krishna, "Enhancing Political Participation...", op. cit., p. 438.

${ }^{19}$ Citados en idem.

${ }^{20}$ K. Brown y R. Brown, "Faith and Works: Church based Social Capital Resources and African American Political Activism”, Social Forces, vol. 82, núm. 2, 2003, pp. 617-641.

${ }_{21}$ D. Nickerson, "Is Voting Contagious? Evidence from Two Field Experiments", The American Political Science Review, vol. 102, núm. 1, 2008, pp. 49-57.

${ }^{22} \mathrm{M}$. Condon, "The Effect of Social Capital on Voter Turnout: A Field Experiment in Two Southwestern Cities", trabajo presentado en el 67 Congreso Anual de la Midwest Political Science Association, Chicago, 2 de abril de 2009.

${ }^{23}$ Klesner, "Who Participates?...”, op. cit.

${ }^{24}$ Teney y Hanquinet, "High Political Participation...", op. cit.

${ }^{25}$ Ikeda y Richey, "Japanese Network Capital...”, op. cit.

${ }^{26}$ K. Ikeda, Y. Yamada y M. Kohno, Influence of Social Capital on Political Participation in Asian Cultural Context, Asian Barometer Working Paper Series 10, Taipéi, National Taiwan University-Academia Sinica, 2003.

${ }^{27}$ Lee, “The Quality of Social...”, op. cit. 
los autores mencionados anteriormente, reconocen diferentes tipos de capital social y de participación política.

Para el caso de China, debido al supuesto control absoluto que ejerce el Partido Comunista sobre la población, de antemano se descartaría el estudio de lo relacionado con la participación política y el capital social. Sin embargo, el control absoluto no existe; en todo caso, la situación china plantea dificultades metodológicas y de acceso a las fuentes.

Una de las características sobresalientes de los chinos es la importancia que dan a las guanxi-relaciones-palancas (关系) como sinónimo de capital social e instrumento en el mundo de los negocios y las interacciones con el gobierno. Se trata de conductas sociales mediante las cuales se crea capital social. ${ }^{28}$ Algunos expertos aseguran que antes de que el concepto de capital social fuera popular en Occidente, su importancia ya era reconocida por los chinos. ${ }^{29}$ Esto es debatible, al menos por la falta de conocimiento al respecto en diversos sectores y momentos. ${ }^{30}$

Destaca el estudio de Hermann-Pillath, ${ }^{31}$ que se apoya, como nosotros, en la información otorgada por la World Values Survey para estudiar China tomando elementos de la economía y de los estudios de área. Al analizar la sociedad desde una perspectiva cultural, examina las guanxi a partir de la triangulación multidisciplinar, lo cual se logra al mezclar enfoques emic y etic. Esto permite formular la hipótesis de que en China surge una forma de capital social culturalmente específica, muy importante para entender la "liga causal entre instituciones y desempeño económico" en ese país. Pese a lo fluido de las relaciones entre el Estado y la sociedad, existen dificultades para la creación de redes y la participación, y esas difi-

${ }^{28}$ X. Chen y Jie Wu, "Do Different Guanxi Types Affect Capability Building Differently? A Contingency View”, Industrial Marketing Management, vol. 40, 2011, pp. 581-592.

${ }^{29}$ K. Chan, "Civil Society and Social Capital in China", en Stefan Toepler y Helmut K. Anheier (eds.), International Encyclopedia of Civil Society, Nueva York, Springer, 2009, pp. 821-825. de 2006.

${ }^{30}$ C. Hamrin, "China’s Social Capital Deficit”, Global China Center, 1 de abril

${ }^{31}$ Carsten Herrmann-Pillath, "Social Capital, Chinese Style: Individualism, Relational Collectivism and the Cultural Embeddedness of the Institutions-Performance Link”, The China Economic Journal, vol. 2, núm. 3, 2009, pp. 325-350. 
cultades son más complejas para unos que para otros; además, las formas y los canales de participación no han sido los mismos que en otras economías.

Uno de los temas que han llamado la atención es el de los migrantes internos, creadores de capital social por excelencia. De acuerdo con un estudio sobre el tema, ${ }^{32}$ que busca influir en las políticas gubernamentales, se especula que el capital social creado por los trabajadores migrantes podría ayudar a cambiar las formas de participación política en China, y se fortalecería si las políticas migratorias estatales se suavizaran. En el mismo campo, hay estudios que investigan la relación entre capital social y migrantes para mostrar los aspectos relacionados con el capital social que desalientan la migración. Según Zhao y Yao, ${ }^{33}$ los entramados sociales locales sirven de estímulo para que los candidatos a migrar prefieran trabajar en el campo, en actividades no agrícolas, antes que salir a buscar el sustento en otra parte.

Al revisar el tema de la participación y el capital social en el caso de China, los problemas de fondo son: primero, las formas en las que se establecen las relaciones con la sociedad; segundo, la capacidad y la voluntad de las organizaciones estatales para cumplir cabalmente con sus obligaciones ante los ciudadanos; tercero, la fuerza de éstos para lograr que el Estado cumpla con sus deberes; y cuarto, la capacidad de organización tanto de las fuerzas sociales como de las estatales.

Los estudios electorales en India se remontan prácticamente al inicio de su vida independiente. A este respecto, Kumar y $\mathrm{Ra}^{34}$ elaboran un recorrido histórico sobre los trabajos del tema, y señalan que en dos de ellos - uno de Sirsikar y otro de Maheshwari- se muestra que a mayor educación, menor confianza e interés en la democracia.

${ }^{32}$ N. Palmer, D. Perkins y Q. Xu, "Social Capital and Community Participation among Migrant Workers in China”, Journal of Community Psychology, vol. 39, núm. 1, 2011, pp. 89-105.

${ }^{33}$ L. Zhao y X. Yao, "Does Local Social Capital deter Labor Migration? Evidence from Rural China", documento de trabajo, Center for Labor, Economics and Public Policy Studies, mayo de 2013.

${ }^{34}$ S. Kumar y P. Rai, Measuring Voting Behavior in India, Los Ángeles, Sage Publications, 2013, pp. 18 y 20. 
Ahuja y Chhibber, ${ }^{35}$ por su parte, se concentran también en el voto. Estudian la motivación de los electores para acudir a las urnas de acuerdo con su estatus socioeconómico, y encuentran que el sufragio es visto en India como un derecho en el caso de los más pobres, mientras que para los que no lo son constituye una obligación o responsabilidad relacionada con la oportunidad de adquirir beneficios a través del desempeño del gobierno.

En cuanto a trabajos que pretenden identificar los determinantes de la participación política en India, en un sentido más amplio que el electoral, destaca el análisis de Krishna, ${ }^{36}$ en el cual construye un índice para cuantificar y explicar la participación política a partir de un levantamiento propio de datos realizado entre 1998 y 2000 en dos estados: Rajasthan y Madhya Pradesh. Este índice se integra mediante diferentes actividades políticas (voto, acciones colectivas en temas públicos, protestas o manifestaciones, principalmente). Las conclusiones arrojan, entre otras cosas, que factores pertenecientes a los niveles meso y micro importan más para explicar la participación política. Asimismo, el capital social genera la cohesión necesaria para la acción colectiva; sin embargo, son los agentes y sus capacidades los que determinan, a través de la información y su dirección, si esta actividad conjunta se orienta a la dimensión política. Este trabajo establece ya la importancia del capital social como elemento unificador de las fuerzas sociales y, por ende, posibilitador de la participación política, sin embargo, lo hace por medio de la construcción de índices que agregan tanto el capital social como la participación.

Spehr y Dutt ${ }^{37}$ enfocan su atención a explicar los determinantes de la participación política específicamente en forma de protesta, debido a la significativa tradición en India. Con datos de la World Values Survey de 1996, identifican la importancia de variables de nivel micro (individual) y meso (grupal). Si

${ }^{35}$ A. Ahuja y P. Chhibber, "Why the Poor vote in India: If I don't vote, I am Dead to the State", Studies in Comparative International Development, vol. 47, 2012, pp. 389-410.

${ }^{36}$ Krishna, "Enhancing Political Participation...”, op. cit., pp. 456-457.

${ }^{37}$ S. Spehr y N. Dutt, "Exploring Protest Participation in India: Evidence from the 1996 World Values Survey”, African and Asian Studies, vol. 3, núm. 3, 2004, pp. 185-218. 
bien no los definen como capital social, sí incluyen elementos como confianza y pertenencia a agrupaciones sociales.

Además, hay otras investigaciones que abonan al conocimiento del tema pero que enfatizan aspectos diversos. Blomkivist $^{38}$ se enfoca en el efecto de la participación política y el capital social en la calidad de la democracia y el desempeño del gobierno. Borooah y Bros $^{39}$ observan el resultado del capital social en la confianza de los votantes en diferentes estructuras públicas y, a través de ella, en la participación política, específicamente en el voto. Mención especial merece la ola de trabajos relativos a la participación política de las mujeres. ${ }^{40}$

En este panorama, los principales retos y problemas que abordan los estudios de la conducta electoral en India corresponden, por una parte, a la heterogeneidad del electorado en diversos términos; y, por otro lado, a la fragmentación de fuerzas políticas y al aumento de partidos ocurrido en la década de 1990 con el fin del predominio del Partido del Congreso. ${ }^{41}$

En ambos casos de estudio, pese la cantidad de trabajos que consideran las variables de interés, es posible identificar las siguientes dificultades para tratar el tema: son escasos o inexistentes los textos que relacionan ambos elementos, o bien no se atienden las diferentes formas de ambos factores; o se identifican diversos tipos de capital social, pero se relaciona con la forma más emblemática de participación según sea el caso. En este sentido es que resulta relevante esta investigación, ya que permite analizar y contrastar la relación entre las formas de participación de los ciudadanos y el tipo de vínculos que

${ }^{38}$ H. Blomkvist, "Social Capital, Political Participation and the Quality of Democracy in India", trabajo presentado en el Congreso Anual de la American Political Science Association, Filadelfia, 28 de agosto de 2003.

${ }^{39}$ V. Borooah y C. Bros, "Confidence in Public Bodies, and Electoral Participation in India”, European Journal of Development Research, núm. 25, 2013, pp. 557-583.

${ }^{40} \mathrm{P}$. Chhibber, "Why are Some Women Politically Active? The Household, Public Space, and Political Participation in India”, International Journal of Comparative Sociology, vol. 43, núm. 3-5, 2002, pp. 409-429; G. Kalita, "Rural Women's Participation in Electoral Politics", IJCAEs Special Issue on Basic, Applied E Social Sciences, vol. 2, 2012, pp. 170-175; V. Nadal, "Participation of Women in Panchayati Raj Institutions: A Sociological Study of Haryana, India", International Research Journal of Social Sciences, vol. 2, núm. 12, 2013, pp. 47-50; A. Gochhayat, "Political Participation of Women in Gram Panchayat Elections in Odisha: A Case Study of Hindol Block in Dhenkanal District”, International Journal of Rural Studies, vol. 20, núm. 2, 2013, pp. 1-7.

${ }^{41}$ Kumar y Rai, Measuring Voting Behavior..., op. cit., pp. 142-143. 
establece la sociedad civil en sistemas políticos distintos. Además, la pertinencia de esta investigación se fortalece porque uno de ellos, el chino, es esencialmente autoritario, sin voto y sin participación política; mientras que el indio sería, por naturaleza, democrático, debido a la participación política electoral, percepciones que no corresponden cabalmente a ninguna de las dos realidades políticas.

\section{Datos, metodología y retos del estudio}

Los casos de estudio fueron seleccionados a partir de la tipología de Lijphart, correspondiente a los tipos denominados "confirmadores o discutidores de teoría", que consisten "en el análisis de un caso como puesta a prueba de una determinada proposición. Su valor teórico se incrementa si se trata de casos en los que ciertas variables se presentan de manera especial". ${ }^{42}$ La idea es identificar si la relación entre las variables se mantiene independientemente del sistema político en que se desenvuelven.

Los datos utilizados provienen de la wvs, cuya ola y fecha de levantamiento varía según el caso, y corresponden a la información disponible más reciente. Para China, el diseño y aplicación del muestreo corrió a cargo del Research Center for Contemporary China de la Universidad de Beijing. Se completaron 2500 encuestas entre adultos de 18 a 75 años de edad residentes en las " 31 [sic] provincias de China continental", pero "Hong Kong, Macao y Taiwan no fueron incluidos". ${ }^{43}$

Los investigadores se basaron en la división oficial de China en siete regiones: noreste, norte, este, centro, sur, noroeste y suroeste. Además, trataron de amortiguar las diferencias campo-ciudad y buscaron que cada estrato de los 14 tomados en cuenta tuviera un número de unidades primarias de muestreo proporcional al tamaño de la población.

${ }^{42}$ R. Kazez, "Los estudios de casos y el problema de la selección de la muestra. Aportes del sistema de matrices de datos”, Subjetividad y Procesos Cognitivos, vol. 13, núm. 1, enero-junio de 2009, p. 77.

${ }^{43}$ World Values Survey, Wave 6, 2010-2014 Official Aggregate v.20140429. World Values Survey Association, Productor asociado: Asep/JDS, Madrid. 
Cabe resaltar que si bien la división fue por regiones, la presentación de los resultados fue por provincia. Esto representa serios problemas de diseño e interpretación por al menos tres razones: por un lado, las divisiones oficiales no corresponden cabalmente a la estructuración histórica y cultural de las regiones; por el otro, deja fuera espacios muy importantes para la comprensión de China, como podrían ser Tianjin y las regiones autónomas. A lo anterior habría que agregar el tema de la etnicidad. Mientras que hacia fuera, por ejemplo al viajar con el pasaporte correspondiente, todos los ciudadanos de China 一中国-zhongguo- son identificados como chinos 一中国 人-zhongguoren-, hacia dentro la diversidad identitaria tiende a crecer pese a lo constreñido que el Estado mantiene lo étnico. No todos los chinos son han, 汉人 hanren, pero se perciben a sí mismos como lo chino y otros también los perciben así. Pese a ello, incluso entre los han hay diferencias considerables. La wvs no tomó en cuenta estos aspectos.

En el caso de India se utilizó la quinta ola, levantada entre diciembre de 2006 y enero de 2007. Aunque ya se llevó a cabo el levantamiento de la sexta ola, sus datos no estaban disponibles cuando se estaba realizando esta investigación. El levantamiento y el diseño corrieron a cargo de la Red Lokniti, que agrupa a académicos de diferentes universidades y centros de investigación. La muestra es aleatoria estratificada multietápi$\mathrm{ca}$, representativa a nivel nacional, y corresponde a 2001 individuos mayores de 18 años. Los encuestados son residentes de 18 de los 28 estados más poblados de India (que concentran $97 \%$ del total de los habitantes). ${ }^{44}$

En cuanto a la metodología, se estimaron modelos probit. Los modelos de variable dependiente binaria como éste permiten observar los aspectos relevantes para explicar la probabilidad de que un fenómeno ocurra o no. A continuación se presenta el modelo estimado, según el cual la probabilidad de participar políticamente en las diferentes formas está en función de las características socioeconómicas del individuo (como género, edad, nivel educativo, tamaño de la población), la satisfacción

${ }^{44}$ World Values Survey, Wave 5, 2005-2008 Official Aggregate v.20140429. World Values Survey Association, Productor asociado: Asep/JDs, Madrid. 
económica que experimenta con su condición actual y el capital social con el que cuenta (expresado en su dimensión tanto de confianza como de redes).

$$
\begin{gathered}
\operatorname{Pr}(\text { participar }=1)=\begin{array}{c}
\Phi\left(\beta+\beta_{1} \text { carac_indiv_socioeco }+\beta_{2}\right. \text { satisf } \\
\left.+\beta_{3} \text { cap_soc }\right)
\end{array} \\
\Phi=\text { distribución_normal }(0,1)
\end{gathered}
$$

En cuanto a las variables, para ambos casos la dependiente -participación política- se operacionalizó de manera que se observen las diferentes formas que adquiere, en consonancia con la definición presentada en el primer apartado y con cuatro de las dimensiones identificadas por Teorell. ${ }^{45}$ En este sentido, se reconocen cinco formas distintas: voto, membresía a partidos políticos, firma de peticiones, participación en boicots y participación en demostraciones pacíficas. Las variables binarias construidas registran si el encuestado ha tomado parte alguna vez en cada una de estas acciones, con excepción del voto, pregunta en la cual se hace referencia específicamente a la actividad durante las últimas elecciones.

El capital social, por otro lado, se operacionalizó a partir de la propuesta teórico-conceptual mostrada en la primera sección, y se distinguen al respecto dos dimensiones: pertenencia a redes y confianza. Este último tratamiento se adoptó a partir del trabajo de Newton, ${ }^{46}$ quien destaca que, pese a que ambos elementos están conceptualmente relacionados de manera cercana, en la práctica hay poca evidencia de que pertenecer a una organización se correlacione con actitudes de confianza a nivel personal. En la parte relativa a redes, a partir de variables binarias se reconoce la participación activa en tres tipos de organizaciones: las relativas a asuntos públicos o laborales (CSB), las vinculadas a fines recreativos o de desarrollo personal (CSDI) y las que atienden propósitos comunitarios (CSDC). Respecto a la confianza, se construyeron dos índices en los que se concentra

${ }^{45}$ Teorell, Torcal y Montero, "Political Participation: Mapping...”, op. cit.

${ }^{46}$ K. Newton, "Trust, Social Capital, Civil Society and Democracy", International Political Science Review, vol. 22, núm. 2, 2001, p. 201. 
la perspectiva del encuestado en torno a la sociedad en general $\mathrm{y}$ a las estructuras gubernamentales (véase cuadro en anexo).

Cabe destacar que la variable relativa a la confianza en estructuras gubernamentales se elevó al cuadrado con el fin de identificar una relación curvilínea respecto a la variable dependiente. Es decir, a partir de trabajos como los de Klasnja y Tucker, ${ }^{47}$ puede suponerse que a mayor desconfianza -o mayor percepción de corrupción-, mayor participación política; sin embargo, se pretende identificar si hay un punto en el nivel de confianza a partir del cual esta relación se invierta. Esta idea tiene su origen en las trampas de pobreza que exponen autores como Razafindrakoto y Roubaud, ${ }^{48}$ en cuyos resultados, conforme se incrementa la percepción de corrupción en los países - que también puede traducirse como desconfianza en las estructuras gubernamentales-, disminuye la participación en política de la población pobre. En este sentido, se esperaría que una mayor confianza en las estructuras gubernamentales esté asociada también con una mayor probabilidad de participar en las formas convencionales, puesto que tradicionalmente se ha asociado la participación no convencional a grupos que experimentan insatisfacción y represión en el orden imperante. ${ }^{49}$

Las variables de control utilizadas son género, edad, nivel educativo y tamaño de la población en la que reside el encuestado. Se incluye también en los modelos estimados una variable relativa al nivel de satisfacción del votante respecto a su situación económica, en referencia a la idea de Gómez y Hansford ${ }^{50}$ respecto a lo poco que se ha investigado cómo el aspecto económico afecta la posibilidad de que los individuos acudan a las urnas.

${ }^{47}$ M. Klasnja y J. Tucker, "The Economy, Corruption and the Vote: Evidence from Experiments in Sweden and Moldova”, Electoral Studies, vol. 32, núm. 3, 2013, pp. 536-543.

${ }^{48}$ M. Razafindrakoto y F. Roubaud, Corruption, Institutional Discredit and Exclusion of the Poor: A Poverty Trap, Afrobarometer Working Papers 86, s.l., Michigan State University-Institute for Democracy in South Africa-Centre for Democratic Development, 2007, pp. 1-36.

${ }^{49}$ Fernández y Rojas, "Escala de acción política...”, op. cit., p. 42.

${ }^{50}$ B. Gómez y T. Hansford, "Economic Retrospection and Voter Turnout", trabajo presentado en el Congreso Anual de la Midwest Political Science Association, Chicago, 22 de abril de 2010. 


\section{¿Quién participa políticamente y cómo lo hace?}

\section{(Auto)percepciones y legitimidad en China: el Estado somos todos}

Algunos grupos europeos y estadounidenses, desde el poder o desde la academia, han impuesto estándares que deberían cumplir los sistemas políticos para pertenecer a tal o cual categoría, como democracia o autoritarismo: votan o no votan. Tales clasificaciones oscurecen la comprensión del funcionamiento del sistema y de la relación entre los Estados y sus gobernados. Un análisis debe tomar en cuenta definitivamente lo que los ciudadanos piensan o perciben de sus gobiernos en cuanto a legitimidad se refiere, ${ }^{51}$ la cual no se obtiene necesariamente en las urnas. Al menos, no solamente en ellas. Por ello, la legitimidad estatal china podría ser mayor que la de muchas democracias.

Socialmente, los seres humanos son construidos de manera desigual en la medida que tienen accesos diferenciados a los recursos de la sociedad. Los regímenes políticos se sostienen a través de relaciones complejas con las personas, tanto en lo individual como en lo grupal. La permanencia en el poder es producto de mecanismos complejos y múltiples, donde la violencia es solamente uno más de los componentes de las relaciones multidireccionales gobierno-gobernados. Uno de los planos de análisis de esas relaciones pasa por el estudio de las (auto)percepciones. Para ello, en esta parte se describen y examinan algunas de las respuestas de personas de la República Popular China proporcionadas a la wvs en su sexta ola, 2010-2014. El estudio de la formación del capital social y de la relación Estado-sociedad debe tomar en cuenta que la encuesta es en gran medida una serie de autopercepciones.

La encuesta, en cuanto a China se refiere, presenta problemas considerables, lo mismo de aplicación que de interpretación. Mientras que a los encuestados se les preguntó sobre su participación en elecciones nacionales, no se les cuestionó espe-

${ }^{51}$ B. Gilley, “The Determinants of State Legitimacy: Results for 72 Countries”, International Political Science Review, vol. XxvI, núm. 1, 2006, pp. 499-526. 
cíficamente, como se hizo en otros países, "por quién votarían si hubiera elecciones mañana" o "qué tan seguido en las elecciones nacionales la TV favorece al gobierno". El 20\% de los interrogados considera que escoger a sus gobernantes es una característica esencial de la democracia, contra $3.4 \%$ que considera exactamente lo opuesto. Cuando se les pregunta si votan cuando hay elecciones nacionales, la mayoría $(74.7 \%)$ contestó que nunca. Mientras que 6.4 y $6.3 \%$ respondieron que siempre y generalmente participaron, respectivamente. Porcentajes similares no respondieron o no sabían. ${ }^{52}$

Por los datos de la wvs, apreciamos que la más importante participación política en China se da en las elecciones locales, seguida de unas elecciones nacionales inexistentes, la firma de peticiones, e intervención en boicots y en manifestaciones. El último lugar lo ocupa la membresía a un partido político, lo cual es comprensible si tomamos en cuenta que el Partido Comunista es selectivo. Con una población de alrededor de 1300 millones de habitantes, el organismo político apenas tiene 86 millones de miembros. Tenemos, institucionalmente, las antípodas en términos de participación creciente, actividad electoral y la ausencia dentro la instancia partidaria.

El sistema político chino tiene lo que se podría considerar una democracia indirecta, más cercana al modelo norteamericano que al mexicano. La elección de los miembros de la Asamblea Popular Nacional china la dirige su Comité Permanente y se realiza en las asambleas de las provincias, regiones autónomas y municipalidades bajo poder del gobierno central. A su vez, tanto el presidente como el vicepresidente son electos por la Asamblea Popular Nacional. ${ }^{53}$ Todo esto hace imposible que haya elecciones nacionales, al menos como se conocen en muchos países. Por un lado, como los organizadores reconocen, no es posible hacer algunas preguntas en ciertos países, dadas las negociaciones entre los encuestadores y las instancias oficiales. Por el otro, hubo respuestas que dieron los encuestados sobre algo inexistente, por razones que no es posible explicar ante la falta de evidencia al respecto.

\footnotetext{
${ }^{52}$ World Values Survey, Wave 6, op. cit.

${ }^{53}$ Asamblea Popular Nacional, Constitution of the People's Republic of China.
} 
Más allá de la inferencia, a partir de estudios académicos, la prensa oficial reporta un desinterés por la participación política ${ }^{54}$ pero también que en el sistema de participación política hay ineficiencias que han conducido "al público a expresar sus demandas a través de peticiones irregulares o incidentes de masas". ${ }^{55}$ Ambos estudios fueron realizados por la Academia de Ciencias Sociales de China. El primero midió, entre otros elementos, el conocimiento de los encuestados sobre sus derechos y su disposición a participar políticamente; el segundo expresa su preocupación por la pobre comunicación funcionarios-población y manifiesta su inquietud sobre el peligro de que se dañe la credibilidad de los gobernantes si ceden a las presiones ejercidas por los manifestantes.

En la gráfica de participación por género, dos aspectos saltan a la vista. El primero es la poca participación a través de los canales planteados por la encuesta, algunos de los cuales son completamente estatales, como las elecciones o el partido; otros canales abren espacios para la independencia política, pero sin convertirse necesariamente en enfrentamientos con la maquinaria estatal, como las manifestaciones. El otro aspecto, como cabría esperar en una sociedad donde los valores tradicionales se han fortalecido con los cambios económicos de más de tres décadas, es la menor intervención de las mujeres. Tanto el Estado como el gobierno acotan esta participación política, incluso dentro de las organizaciones tradicionales, como es el caso emblemático del Partido Comunista, cuya membresía es pequeña y dominada por los hombres. Tenemos tres rubros donde la participación bien puede ser independiente pero dirigida a interactuar con las instancias estatales, aunque no siempre: petición, boicot y manifestación. En todos, la participación es predominantemente masculina, pero reducida. Lo interesante es señalar que la información arroja un porcentaje creciente de encuestados que estarían dispuestos a incrementar su intervención. El único elemento que no cambia es el

\footnotetext{
${ }^{54}$ Xinhua, "Low Political Participation among Chinese", China Daily, 1 de septiembre de 2012.

${ }^{55}$ Y. Zhang, "Inefficient Public Participation in Politics", Global Times, 7 de agosto de 2013.
} 
de la asimetría de género. La participación femenina continuaría siendo menor que la de los hombres.

En la gráfica 1 se ven los tres tipos de capital social distribuidos por género: individual, grupal y bivalente. La información expresa dos aspectos importantes: confirma el peso del género masculino en la creación de capital social y la mayor fuerza del

\section{GRÁFICA 1. Capital social por género en China}

\section{Porcentajes}

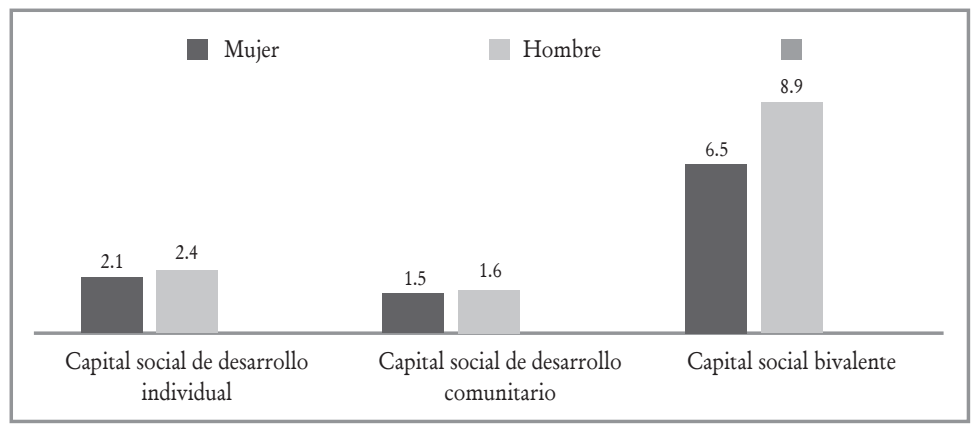

GRÁFICA 2. Participación política por género en China

Porcentajes

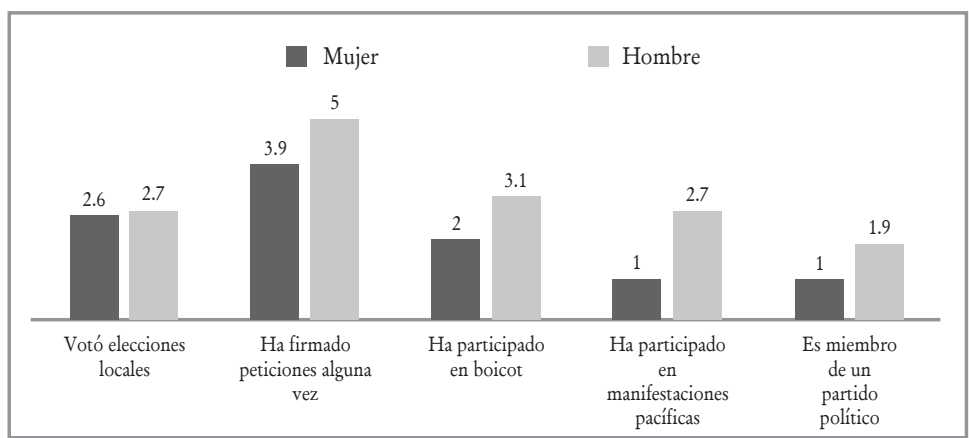

Fuente: Elaboración propia con datos de la World Values Survey, Wave 6, 20102014 Official Aggregate v.20140429. World Values Survey Association, productor asociado: Asep/JDS, Madrid. 
CUADRO 2. Porcentaje de personas asociadas a organizaciones del total de electores que participa políticamente en China

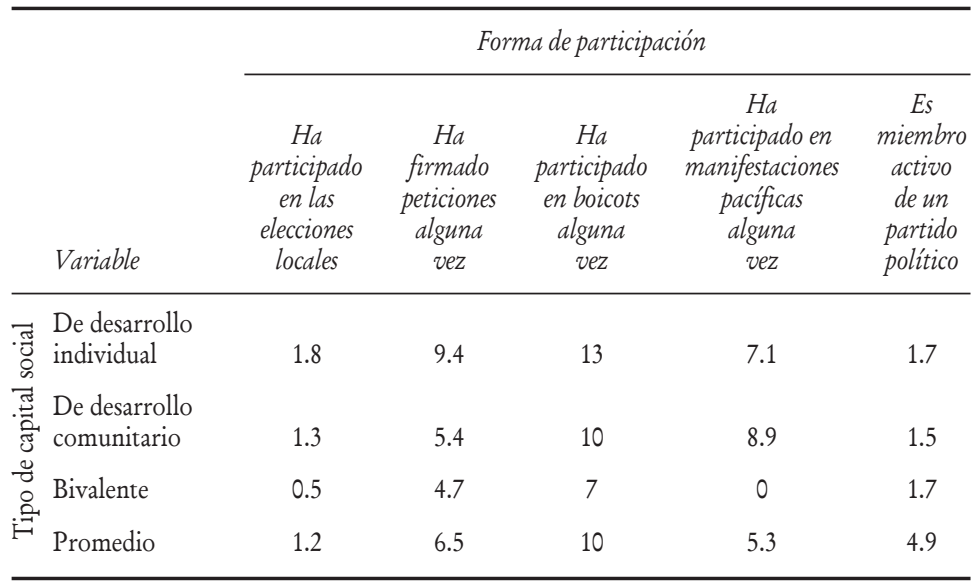

Fuente: Elaboración propia con datos de la World Values Survey, Wave 6, 20102014 Official Aggregate v.20140429. World Values Survey Association, productor asociado: Asep/JDs, Madrid.

individuo sobre el grupo. No obstante el peso del individualismo, cabe destacar los valores relacionados con la tradición que favorecen la creación de capital social, tal es el caso de la confianza, que ya fue subrayada en otro estudio. ${ }^{56}$

El punto más sobresaliente en el cuadro 2 es la poca participación institucionalizada bajo la forma de partido o en elecciones vinculada al capital social. Por el contrario, en los tres niveles la pertenencia a organizaciones se relaciona con expresiones políticas poco estructuradas, donde sobresale la colaboración en boicots. El cuadro muestra, en suma, que la relevancia del capital social está, presumiblemente, orientada a la participación vía mecanismos informales y efímeros.

En el cuadro 3 se observa que el género influye en el voto local y en la participación en acciones pacíficas; ser hombre aumenta la probabilidad de participar. La mayor edad, por su parte, tiene una relación negativa con la participación en

${ }^{56}$ Herrmann-Pillath, “Social Capital, Chinese Style...”, op. cit. 
marchas, es decir, la gente joven es más proclive a este tipo de acciones; sin embargo, en cuanto a la pertenencia al partido, hay mayor probabilidad de pertenecer conforme la edad aumenta. De acuerdo con la información disponible, es sobre todo un asunto de mayores de 30 años.

Destaca también que las posibilidades de que alguien firme una petición están asociadas a un mayor nivel educativo, mientras que los que participan en acciones políticas más directas, como una marcha, serían los "menos educados". De igual forma ocurre con la pertenencia al partido, la cual está relacionada con la educación, ya que los universitarios serían los más propensos a engrosar sus filas.

No deja de llamar la atención que los más satisfechos en cuanto a las finanzas de su hogar sean los más propensos a participar en manifestaciones pacíficas. Esto resulta interesante porque es la expresión política más estigmatizada por el gobierno y en la que la sociedad ha sido más reprimida. No obstante, en términos de autopercepción es un aspecto positivo. Por otra parte, los inconformes con su situación económica son más propensos a participar en actividades de boicot.

En términos de confianza en la sociedad, tenemos que, de acuerdo con la forma en que está construida la variable (escala en la que mayores valores reflejan más desconfianza; véase anexo), los que más confianza tienen en la sociedad serían los más propensos a afiliarse al partido. De manera opuesta, el resto de las formas de participación (voto local, firma de peticiones y marchas pacíficas) están relacionadas positivamente con la desconfianza social. A su vez, la desconfianza en el gobierno influiría en la participación en boicots.

Sin pretender agotar el análisis, es preciso anotar algunos comentarios sobre los tipos de capital propuestos para este trabajo. En cuanto a capital para el desarrollo personal, encontramos significancia estadística para la firma de peticiones y participación en boicots, y en menor medida para la inclusión en manifestaciones y membresía al partido. En la variable para el desarrollo grupal, la relevancia está en la pertenencia al partido, manifestaciones pacíficas y, en menor medida, en la disposición a participar en un boicot. En cuanto al capital bivalente, tenemos una incidencia similar, pero con mayor signi- 


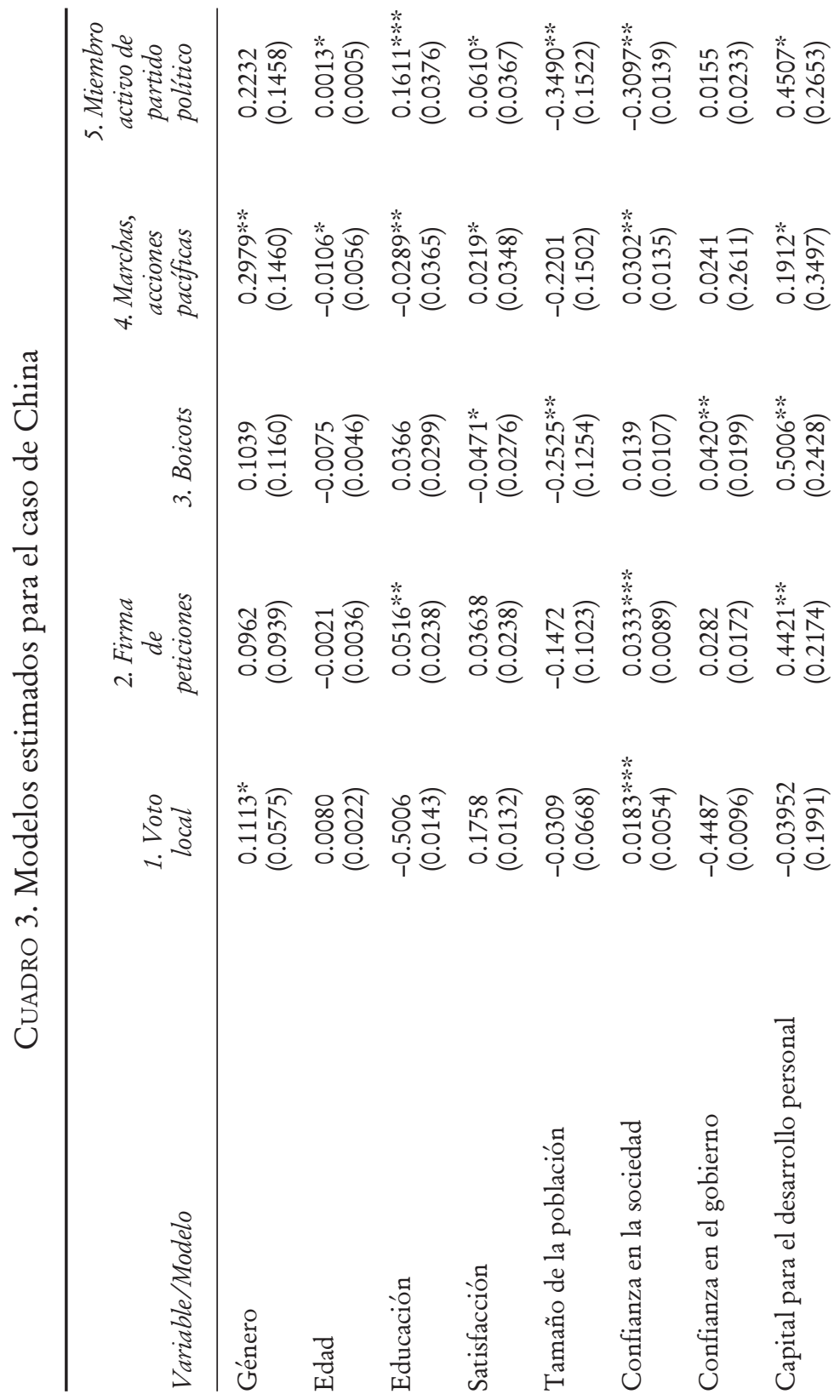


HARO-TAPIA: SOCIEDAD, PARTICIPACIÓN POLÍTICA Y...

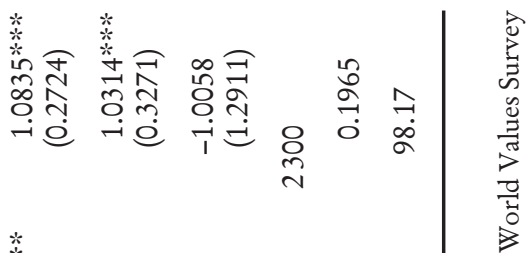

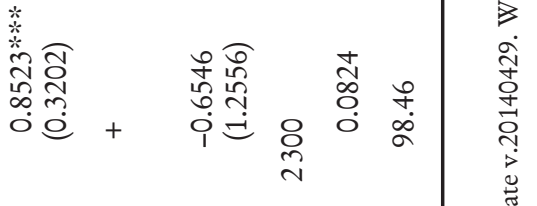

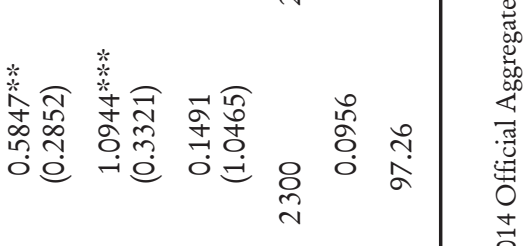

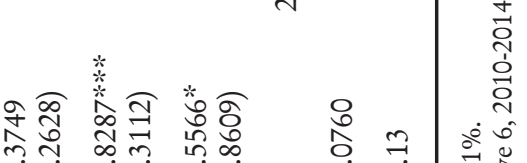

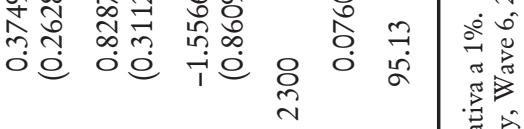

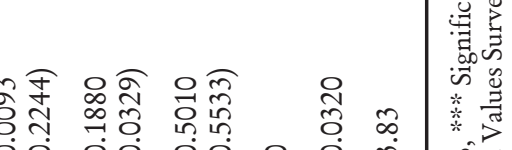

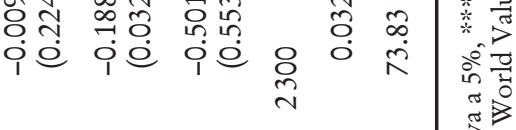

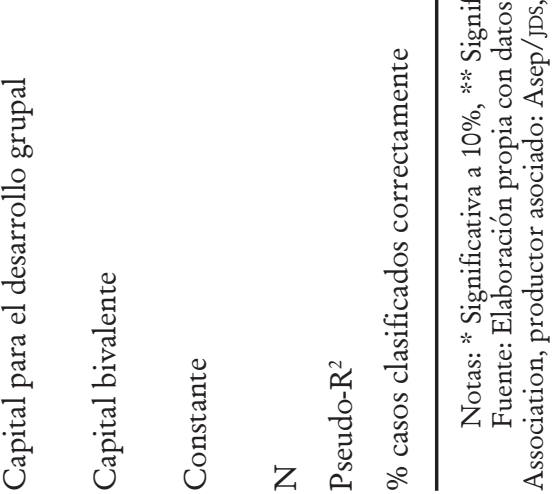


ficancia y magnitud en todas las formas de participación, con excepción del voto.

La evidencia, con todas sus limitantes, confirma que la encuesta tiene debilidades considerables y que la democracia electoral occidental no existe en China; no obstante, sí hay participación política y se puede constatar que el Estado son todos, al menos una parte considerable, lo cual incluye a los que no pertenecen institucionalmente a él.

\section{El caso de India: "el voto es nuestra arma"57}

El inicio de la vida independiente india estuvo impregnado de una gama de valores idealistas, y resalta la importancia de la libre determinación de los pueblos y la solidaridad entre éstos. Desde ese momento hasta el 2015, es posible decir que la sociedad civil ha construido una tradición de protesta y lucha anticolonialista en medio de agudos problemas de pobreza y corrupción. Contrariamente a lo que ocurre en los países desarrollados, este panorama ha alentado la participación política.

Los niveles de participación electoral en India son sumamente altos. De acuerdo con los datos de la World Values Survey, ${ }^{58}$ aproximadamente nueve de cada 10 encuestados acudió a las urnas en las últimas elecciones. El voto es visto como “arma” para expresar demandas e incidir en el destino del país, como un derecho que debe ser ejercido. ${ }^{59}$ Después del sufragio, la firma de peticiones constituye la opción más popular, con una incidencia de $22.64 \%$. La membresía activa a partidos políticos, las manifestaciones públicas pacíficas y los boicots constituyen prácticas menos generalizadas entre los habitantes, quienes refirieron en la materia tasas de participación de 17.54, 14.99 y $11.74 \%$ respectivamente.

Para entender lo anterior, es importante recordar dos aspectos: primero, que pese a los años de antigüedad que posee

${ }^{57}$ M. Banerjee, "Democracy”, en Nicholas Kitchen (ed.), India: The Next Superpower, Londres, London School of Economics and Political Science, 2012, p. 47.

${ }^{58}$ World Values Survey, Wave 5, op. cit.

${ }^{59}$ Banerjee, "Democracy", op. cit., p. 47. 
la democracia en India, no es sino hasta finales de la década de 1990 cuando se convierte realmente en un sistema multipartidista. Esto abre paso a un sistema de coaliciones, ya que las castas "más bajas" surgen como una fuerza política importante que anteriormente había sido invisibilizada por la élite políticamente dominante. En segundo lugar, hay una elevada confianza en el organismo encargado del proceso electoral, la Comisión Electoral India. ${ }^{60}$

De acuerdo con Drèze y Sen, ${ }^{61}$ la democracia de la Unión concentra instituciones electorales que "quedan en buen lugar a la luz de los criterios internacionales"; sin embargo, está ensombrecida por aspectos como la cultura laboral de los políticos y los tratos ilícitos para la obtención de fondos. Pese a esto, ambos sostienen que los resultados de las encuestas muestran un alto porcentaje de la población a favor de la democracia.

Al observar la participación política por género, resalta que, como era de esperarse, la proporción de mujeres involucradas en el tema es prácticamente la mitad de la correspondiente a los hombres; esto se mantiene en todas las formas de acción analizadas, con excepción del voto. Tal como lo refiere Lal, ${ }^{62}$ los hechos violentos contra mujeres ocurridos durante 2012 representaron un parteaguas y dieron auge al tema e incentivaron diferentes medidas para mejorar la situación. En este sentido, si bien la autora señala que el país ha signado diferentes instrumentos internacionales para garantizar la igualdad, recuerda también que las cifras en varios temas muestran una realidad adversa para el género femenino. La dimensión política no es la excepción.

En cuanto a capital social, si lo cuantificamos a partir de la afiliación a grupos u organizaciones, se observa que en general uno de cada tres hombres pertenece a este tipo de estructuras, mientras que la proporción se reduce en el caso de las mujeres: una de cada cinco. Asimismo, la proporción tanto de hombres como de mujeres con capital social para el desarrollo personal es prácticamente igual a la que corresponde al capital

${ }^{60}$ Ibid., p. 46.

${ }^{61}$ Drèze y Sen, Una gloria incierta..., op. cit., pp. 278-279.

${ }^{62}$ Lal Neeta, "Participación política de mujeres a la zaga en India", Inter Press Service Agencia de Noticias, 1 de julio de 2014. 
social para el desarrollo grupal o comunitario (gráfica 4). El capital social bivalente refleja una menor inclusión de los individuos, casi uno de cada cinco hombres, quienes pertenecen a este tipo de organizaciones.

Al identificar la proporción de personas pertenecientes a organizaciones, del total de las que participan políticamente de diversas formas, se aprecia que en el caso del voto el porcentaje es el más reducido de todos: en promedio, una de cada cinco personas que acude a las urnas es miembro de algún tipo de grupo. Al diferenciar por tipo capital social —dejando de lado

GráfICA 3. Porcentaje de hombres y mujeres que participan políticamente

India 2006

\begin{tabular}{|cccccc|}
\hline 口ujer & \multicolumn{4}{c|}{ Hombre } \\
\hline $\begin{array}{c}\text { Votó en } \\
\text { las últimas } \\
\text { elecciones }\end{array}$ & $\begin{array}{c}\text { Ha firmado } \\
\text { peticiones } \\
\text { alguna vez }\end{array}$ & $\begin{array}{c}\text { Ha participado } \\
\text { en boicots } \\
\text { alguna vez }\end{array}$ & $\begin{array}{c}\text { Ha } \\
\text { participado en } \\
\text { manifestaciones } \\
\text { pacíficas alguna } \\
\text { vez }\end{array}$ & $\begin{array}{c}\text { Es miembro } \\
\text { activo de } \\
\text { un partido } \\
\text { politico }\end{array}$ \\
\hline
\end{tabular}

Gráfica 4. Capital social por género

India 2006

\begin{tabular}{|c|c|c|c|c|}
\hline \multirow[b]{3}{*}{$21 \%$} & & & \multicolumn{2}{|l|}{ Hombre } \\
\hline & $32 \%$ & \multirow[b]{2}{*}{$23 \%$} & \multirow{2}{*}{$13 \%$} & \multirow[b]{2}{*}{$18 \%$} \\
\hline & & & & \\
\hline \multicolumn{2}{|c|}{$\begin{array}{c}\text { Capital social } \\
\text { de desarrollo } \\
\text { individual }\end{array}$} & $\begin{array}{l}\text { Capita } \\
\text { de des } \\
\text { comu }\end{array}$ & \multicolumn{2}{|c|}{$\begin{array}{c}\text { Capital social } \\
\text { bivalente }\end{array}$} \\
\hline
\end{tabular}

Fuente: Elaboración propia con datos de la World Values Survey, Wave 5, 20052008 Official Aggregate v.20140429. World Values Survey Association, productor asociado: Asep/JDs, Madrid, para el caso de India. 
CuAdro 4. Porcentaje de asociados a organizaciones del total de electores que participa políticamente en India

\begin{tabular}{|c|c|c|c|c|c|c|}
\hline & \multirow[b]{2}{*}{ Variable } & \multicolumn{5}{|c|}{ Forma de participación } \\
\hline & & $\begin{array}{c}\text { Votó } \\
\text { en las } \\
\text { últimas } \\
\text { elecciones }\end{array}$ & $\begin{array}{c}\text { Ha } \\
\text { firmado } \\
\text { peticiones } \\
\text { alguna } \\
\text { vez }\end{array}$ & $\begin{array}{c}H a \\
\text { participado } \\
\text { en boicots } \\
\text { alguna } \\
\text { vez }\end{array}$ & $\begin{array}{c}H a \\
\text { participado en } \\
\text { manifestaciones } \\
\text { pacíficas } \\
\text { alguna } \\
\text { vez }\end{array}$ & $\begin{array}{c}\text { Es } \\
\text { miembro } \\
\text { activo } \\
\text { de un } \\
\text { partido } \\
\text { político }\end{array}$ \\
\hline \multirow{5}{*}{ 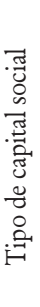 } & $\begin{array}{l}\text { De desarrollo } \\
\text { individual }\end{array}$ & 27.44 & 47.24 & 51.06 & 51.33 & 64.1 \\
\hline & $\begin{array}{l}\text { De desarrollo } \\
\text { comunitario }\end{array}$ & 28.99 & 46.14 & 48.51 & 50.67 & 65.81 \\
\hline & Bivalente & 15.57 & 26.71 & 35.32 & 32 & 51.57 \\
\hline & Los tres anteriores & 10.93 & 21.63 & 22.55 & 23.67 & 48.15 \\
\hline & Promedio & 20.73 & 35.43 & 39.36 & 39.41 & 57.40 \\
\hline
\end{tabular}

Fuente: Elaboración propia con datos de la World Values Survey, Wave 5, 20052008 Official Aggregate v.20140429. World Values Survey Association, productor asociado: Asep/JDS, Madrid, para el caso de India.

la dimensión relacionada con la confianza y limitándonos a la asociación-, se observa que esta medida se incrementa y llega a casi uno de cada tres en el caso del tipo "para el desarrollo grupal" y desciende hasta $15.57 \%$ en el que llamamos bivalente. Los datos contenidos en el cuadro 4 permiten pensar que el capital social constituye un factor importante en el perfil de los ciudadanos que participan políticamente a través de formas alternativas al voto, especialmente en los partidos políticos. A continuación, el cuadro 5 sintetiza los resultados de los modelos probit estimados para contrastar esta hipótesis.

En relación con los aspectos que modifican la probabilidad de que un ciudadano vote en India, se observa que la edad y el nivel educativo resultan significativos. A más años, tanto de edad como de educación académica, el elector es más proclive a acudir a las urnas. Sin embargo, en el caso de la edad, esta tendencia se revierte al llegar a los 58 años, aproximadamente, punto a partir del cual con cada año adicional la probabilidad 


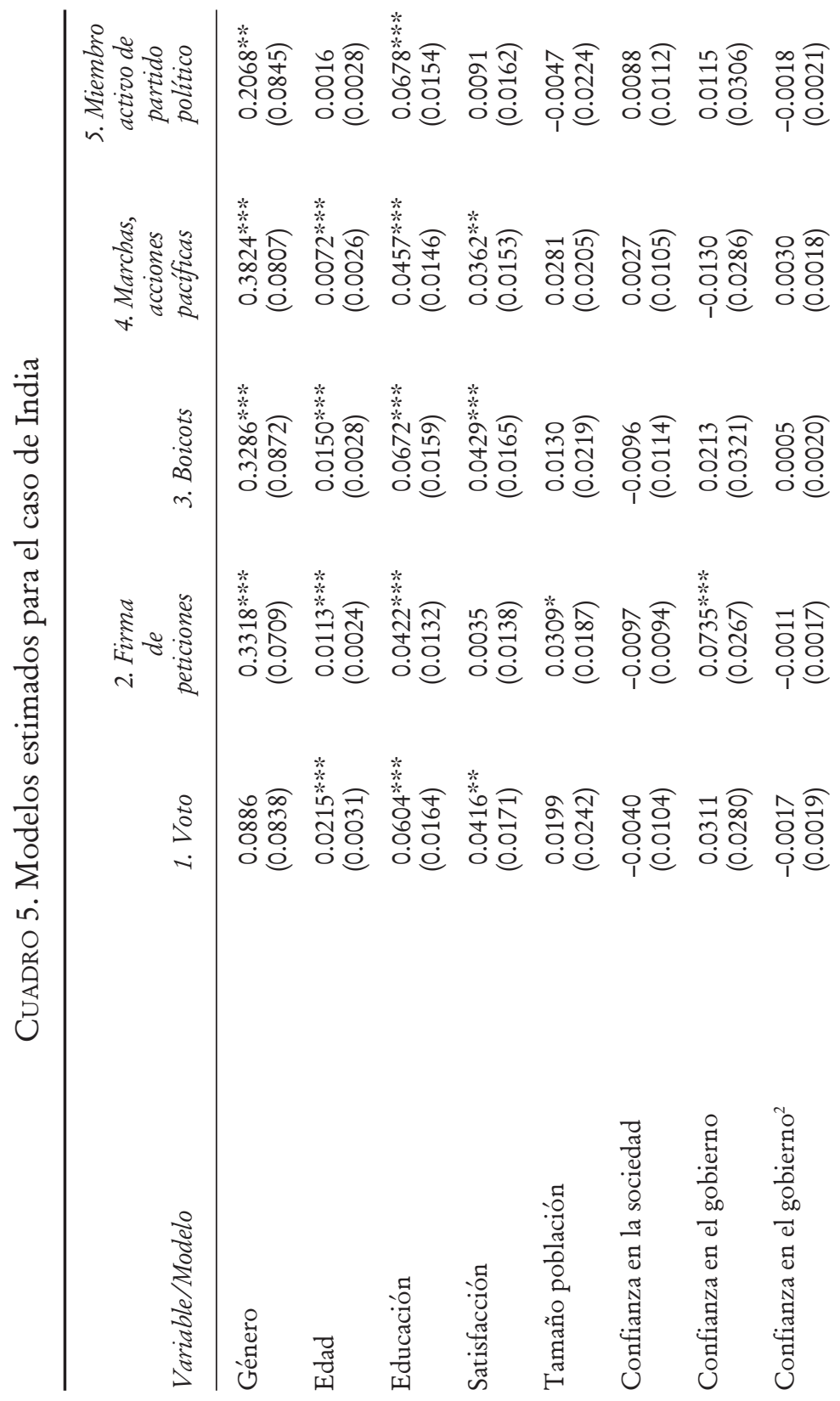


HARO-TAPIA: SOCIEDAD, PARTICIPACIÓN POLÍTICA Y...

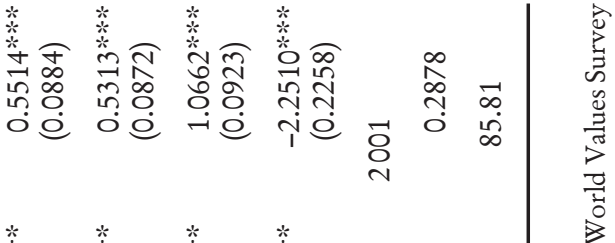

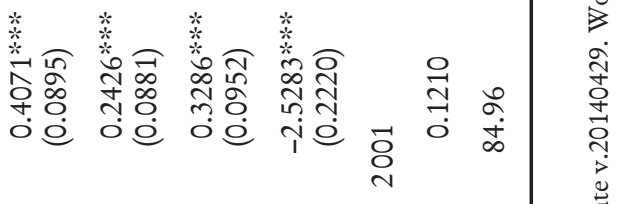

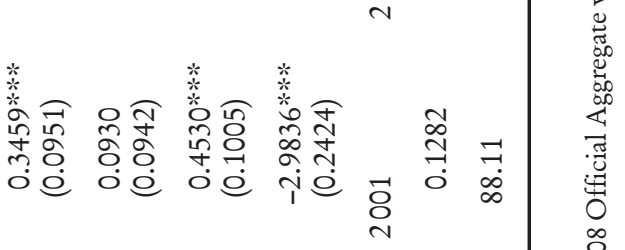

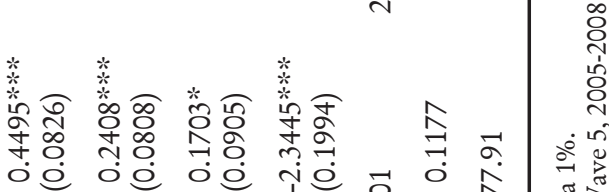

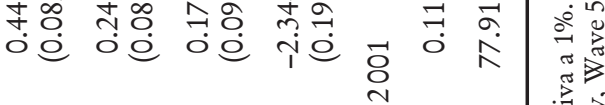

$$
\begin{aligned}
& \text { í }
\end{aligned}
$$

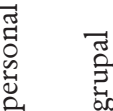

$$
\begin{aligned}
& \text { 응 은 }
\end{aligned}
$$

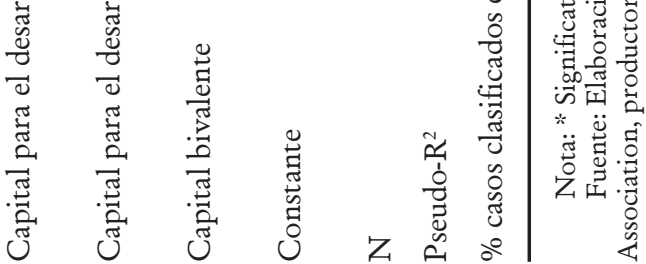


decrece. ${ }^{63}$ Es de destacar que el capital social (tanto en la dimensión de pertenencia a redes como en la de confianza) no parece impactar la probabilidad de que los habitantes voten. Sin embargo, el nivel de satisfacción por la situación financiera del hogar es relevante, de manera que, a mayor satisfacción, mayor disposición de emitir el sufragio; esto podría interpretarse como una forma de legitimar o expresar aceptación respecto al funcionamiento de las instituciones políticas.

Al estudiar a los votantes que han firmado peticiones, se observa que la probabilidad de pertenecer a este grupo aumenta conforme a la edad, la escolaridad y el número de habitantes en el lugar de residencia. Asimismo, los hombres son más propensos a participar políticamente de este modo.

En cuanto a las variables de interés, se aprecia, en contraste con el caso del voto, que el capital social en su dimensión asociativa o de pertenencia impacta positivamente la probabilidad de haber firmado peticiones (independientemente del tipo de éstas); mientras que en su dimensión de confianza en las estructuras gubernamentales, lo hace negativamente. Es decir, a mayor desconfianza en el gobierno, mayor probabilidad de participar en la firma de peticiones.

Si bien los tres tipos de capital social identificados en este trabajo resultan estadísticamente significativos, es importante subrayar que no repercuten en el fenómeno con la misma magnitud. Así, el efecto positivo del capital social para el desarrollo personal en la probabilidad de haber firmado peticiones es de 13.42 puntos porcentuales, mientras que el que corresponde al capital social para el desarrollo grupal o bivalente es de prácticamente la mitad (6.93 y $4.93 \%$ respectivamente).

La probabilidad de tomar parte tanto en boicots como en manifestaciones pacíficas se relaciona positivamente con el género masculino, la edad y el nivel educativo. En materia de capital social, se observa que la dimensión relativa a la confianza no resultó significativa para estas formas de participación política; sin embargo, la que corresponde a pertenencia, sí. Ser miembro activo de asociaciones para el desarrollo personal y

${ }^{63}$ Esto último se observó al estimar el modelo que se presenta agregando la variable "edad" elevada al cuadrado. En lo que compete al resto de las variables, las conclusiones que se desprenden de ambos modelos son prácticamente las mismas. 
uniones laborales (bivalente) aumenta la proclividad a tomar parte en boicots, pero el capital social de tipo desarrollo grupal (es decir, pertenencia a organizaciones ambientales, religiosas y caritativas) no incide en este tipo de conducta. En el caso de las manifestaciones pacíficas, se relacionan positivamente con los tres tipos de capital social.

Constituirse en miembro activo de un partido político se relaciona positivamente con el género masculino y el nivel educativo; tal como las formas anteriores de participación. Destaca la importancia del capital social en su dimensión de pertenencia para esta faceta del fenómeno, ya que ser miembro de asociaciones del tipo bivalente aumenta en $29.60 \%$ la probabilidad de participar políticamente de esta forma.

En India, el capital social, en su dimensión asociativa, influye en prácticamente todas las formas de participación, excepto en el voto, y además hay otra diferenciación: el capital para el desarrollo grupal no es significativo para la probabilidad de participar en boicots. Los resultados permiten inferir que, a partir de la manera en que el voto es entendido, y de su generalización, esta forma de participación no está influida por las redes personales o la confianza; sin embargo, en contraste, las formas de participación no convencional sí se relacionan (en su mayoría) con las redes sociales que las incentivan o posibilitan (por el carácter "colectivo" de estas prácticas: marchas, boicots, entre otras).

\section{Reflexiones finales sobre el Estado y la participación: diferentes formas de capital social}

La evidencia de una disolución parcial del Estado en China y una mayor participación política social se hace patente en muchos campos. Desde el punto de vista histórico, el sistema político chino nace diseñado y apuntalado por un partido militarizado que, por lo tanto, funcionó como un ejército. La participación política en China siempre ha sido importante y alentada por el Estado, pero bajo su férula. Las estructuras estatales han hecho corporativas las actividades políticas y económicas a través, por ejemplo, de los sindicatos, las comunas 
o las unidades de trabajo. De hecho, las élites políticas han tratado de diseñar una sociedad verticalmente estratificada bajo criterios económicos, pero en realidad se trata de crear una estructura social con un eje fundamental en la lealtad al Partido Comunista.

Las fuentes consultadas y su análisis permiten aseverar que la relación sociedad-Estado es más compleja que una de mera dominación estatal sobre la sociedad. Diferentes grupos sociales han impulsado, de manera tanto individual como colectiva, la creación de capital social y, así, la participación en diferentes canales políticos. Unos son más abiertos, como los procesos electorales locales, mientras que otros son considerablemente cerrados, como el ingreso al partido gobernante. Además, es posible anotar que esa misma sociedad se abre sus propios espacios para la participación política y la creación de capital social, lo cual la lleva a enfrentarse circunstancialmente al Estado. Al mismo tiempo, hemos apreciado que, frente a los cambios, hay aspectos del pasado que no se pueden dejar atrás, como es el peso mayor y persistente del género masculino frente al femenino. Por lo demás, los procesos electorales merecen mayor atención en los análisis de participación política y formación de capital social de los chinos. ${ }^{64}$

Contrastar información recurriendo a varias fuentes nos lleva a considerar que la participación política es mayor que lo que la wvs permitiría afirmar, pero no hemos ahondado aún al respecto por las cuestiones conceptuales y metodológicas planteadas desde el inicio. Sin embargo, hay que anotar que la creciente búsqueda social para enfrentar los problemas, como los ambientales, lleva a algunos sectores de la población a salirse de los canales formales al no haber instituciones adecuadas para canalizar la participación y atender las demandas de la población. La ganancia fundamental es la creación de capital social.

Una de las limitaciones metodológicas más importantes tiene que ver con las características de la wvs en su sexta ola, que presenta problemas de varios tipos para el caso de China. El primero se refiere a las preguntas que no se formularon

${ }^{64} \mathrm{~J}$. Tomm, "Village and Township Elections in China. Elements of Democratic Governance”, A Journal on Politics, vol. 1, núm. 2, 2006, pp. 85-95. 
adecuadamente, como las correspondientes a etnicidad, que en China es clave para entender la composición demográfica y los cambios identitarios de por lo menos los últimos 30 años. El proceso de construcción identitaria impide resolver el tema solamente con lo relativo a la nacionalidad. Estrechamente ligado a lo anterior tenemos la cuestión espacial de aplicación de la wVs. La primera impresión es que los responsables optaron por concentrase en el espacio cultural chino en sentido restringido, lo han mayoritario y chino en contraposición excluyente a las denominadas minorías nacionales folclóricas contenidas en los márgenes de las fronteras culturales de lo chino-ban.

No obstante lo anterior, la wvs para China abre resquicios para asomarse a los espacios donde cristaliza la formación de capital social y sus actores en ese proceso. En una sociedad dominada políticamente por un partido y masculinizada, la participación política es parte de la vida cotidiana del país, sobre todo a través de la firma de peticiones, aunque otras formas no están ausentes.

En India, el voto está profundamente extendido entre la población como un derecho que es necesario e importante ejercer, por lo que otras formas de participación, pese a tener una larga historia en el país, no están tan generalizadas. Es posible decir que el capital social influye positivamente en cualquier tipo de movilización política; sin embargo, su impacto está diferenciado entre las formas de esta última; no incide en la propensión a votar, pero sí en cualquier otro tipo de acción.

Una de las limitaciones de este caso también está relacionada con la información. Es importante destacar que en el capital social influyen dos elementos centrales: las castas y la religión; a mayor heterogeneidad, menor confianza y menor capital social. ${ }^{65} \mathrm{~A}$ partir de esta relación, otros autores reconocen que los partidos políticos han concentrado sus esfuerzos en ganar el voto de bloques sociales cohesionados por la casta, lo que ha derivado en una "política de banco de votos", que si bien ha otorgado poder a los menos favorecidos, también ha privilegiado

${ }^{65}$ J. Sengupta y S. Debnarayan, "Caste and Religious Diversity on Formation of Social Capital”, Equality, Diversity and Inclusion: An International Journal, vol. 31, núm. 2, 2012, pp. 158-175. 
intereses de grupo con una visión de corto plazo. ${ }^{66}$ Sin embargo, en este trabajo no se integró este tipo de análisis, ya que la fuente utilizada no presentaba datos al respecto en el momento de su elaboración.

Ante la pregunta establecida inicialmente en este texto, es posible apreciar que, pese a las diferencias entre los sistemas políticos de China e India, el capital social incide en la participación política y lo hace de manera diversa según su tipo. De acuerdo con la evidencia, ambos casos muestran que el voto, como signo clave de la participación convencional, no se relaciona con ningún elemento relativo al capital social; sin embargo, obedece a razones diferentes: en uno de los extremos (India) esta práctica está presumiblemente "internalizada" en los ciudadanos, pues el significado que reviste (como derecho o incluso como arma) eclipsa la necesidad de incentivos creados por la colectividad (influencia de las redes) o bien por la autoridad misma. Por otro lado, en China la carencia generalizada de esta práctica provoca que, como se expuso, lo interesante del análisis sean las respuestas emitidas por los encuestados.

Respecto a las formas de participación social no convencionales, los dos países reflejan la importancia del capital social en su dimensión asociativa (incidencia positiva), ya sea del tipo de desarrollo personal, grupal o bivalente. En cuanto a la confian$\mathrm{za}$, ambos casos comparten participaciones no convencionales asociadas a la desconfianza en el gobierno; sin embargo, la forma que revisten es distinta: mientras que en China deriva en boicot, en India solamente remite a firma de peticiones.

Finalmente, otro contraste se produce entre China e India al analizar la dimensión relativa a la confianza: en el primer caso, la desconfianza en la sociedad se relaciona con todo tipo de participación, excepto la pertenencia al partido (que se vincula a la confianza), mientras que, en el caso de India, este elemento no resulta relevante según los datos.

Ante estas diferencias y similitudes, cabe cuestionarse sobre las historias que subyacen a los datos numéricos. Esto representa, desde nuestra perspectiva, una línea sobre la que se

${ }^{66}$ A. Narain, "La India trata de resolver el problema de castas por medio del federalismo”, Federaciones, vol. 5, núm. 3, 2006, p. 24. 
deberá trabajar para enriquecer no sólo el análisis, sino también la comprensión de los hallazgos alcanzados y las interrogantes aún pendientes sobre el tema.

Dirección institucional de los autores:

Universidad de Colima

Avenida Universidad 333

Las Víboras

28040, Colima, México

\section{Bibliografía}

Ahuja, A. y P. Chhibber, "Why the Poor vote in India: If I don't vote, I am Dead to the State", Studies in Comparative International Development, vol. 47, núm. 4, 2012, pp. 389-410.

Arriagada, I., Breve guía para la aplicación del enfoque de capital social en los programas de pobreza, Santiago de Chile, Comisión Económica para América Latina y el Caribe, 2006.

Asamblea Popular Nacional, Constitution of the People's Republic of China. [<english.people.com.cn/constitution/consitution. html >, consultado el 26 de julio, 2014.]

BAnerJee, M., "Democracy", en Nicholas Kitchen (ed.), India: The Next Superpower, Londres, London School of Economics and Political Science, 2012.

Blomkvist, H., "Social Capital, Political Participation and the Quality of Democracy in India”, trabajo presentado en el Congreso Anual de la American Political Science Association, Filadelfia, 28 de agosto de 2003.

Boroonh, V. y C. Bros, "Confidence in Public Bodies, and Electoral Participation in India", European Journal of Development Research, vol. 25, núm. 4, 2013, pp. 557-583.

BRADY, H., S. Verba y K. Schlozman, "Beyond SEs: A Resource Model of Political Participation", The American Political Science Review, vol. 89, núm. 2, 1995, pp. 271-294.

Brown, K. y R. Brown, "Faith and Works: Church based Social Capital Resources and African American Political Activism", Social Forces, vol. 82, núm. 2, 2003, pp. 617-641.

Chan, K., "Civil Society and Social Capital in China", en Stefan Toepler y Helmut K. Anheier (eds.), International Encyclopedia of Civil Society, Nueva York, Springer, 2009, pp. 821-825. 
Chen, X. y Jie Wu, "Do Different Guanxi Types Affect Capability Building Differently? A Contingency View", Industrial Marketing Management, vol. 40, núm. 4, 2011, pp. 581-592.

ChHibber, P., "Why are Some Women Politically Active? The Household, Public Space, and Political Participation in India", International Journal of Comparative Sociology, vol. 43, núm. 35, 2002, pp. 409-429.

Condon, M., "The Effect of Social Capital on Voter Turnout: A Field Experiment in Two Southwestern Cities", trabajo presentado en el 67 Congreso Anual de la Midwest Political Science Association, Chicago, 2 de abril de 2009.

Drèze, J. y A. Sen, Una gloria incierta: India y sus contradicciones, Madrid, Taurus, 2014.

DuRston, J., ¿Qué es capital social comunitario?, Serie Políticas Sociales, núm. 38, Santiago de Chile, Comisión Económica para América Latina y el Caribe, 2000.

Ekman, J. y E. Amna, "Political Participation and Civic Engagement: Towards a New Typology", Human Affairs, vol. 22, núm. 3, 2012, pp. 283-300.

FERNÁNDEZ, J. y A. J. Rojas, "Escala de acción política no convencional. Análisis de fiabilidad y validez", Psicología Política, núm. 26, 2003, pp. 41-55.

Gilley, B., "The Determinants of State Legitimacy: Results for 72 Countries", International Political Science Review, vol. 27, núm. 1, 2006, pp. 499-526.

Gochhayat, A., "Political Participation of Women in Gram Panchayat Elections in Odisha: A Case Study of Hindol Block in Dhenkanal District", International Journal of Rural Studies, vol. 20, núm. 2, 2013, pp. 1-7.

Gómez, B. y T. Hansford, "Economic Retrospection and Voter Turnout", trabajo presentado en el Congreso Anual de la Midwest Political Science Association, Chicago, 22 de abril de 2010.

Hamrin, C., "China's Social Capital Deficit", Global China Center, 1 de abril de 2006. [ < http://www.globalchinacenter.org/analysis/chinese-society-politics/chinas-social-capital-deficit.php $>$, consultado el 21 de julio de 2014.]

Herrmann-Pillath, Carsten, "Social Capital, Chinese Style: Individualism, Relational Collectivism and the Cultural Embeddedness of the Institutions-Performance Link", The China Economic Journal, vol. 2, núm. 3, 2009, pp. 325-350. [< http://ssrn.com/ abstract $=1481192>$, consultado en marzo de 2016.]

IkEDA, K. y S. Richey, "Japanese Network Capital: The Impact of 
Social Networks on Japanese Political Participation”, Political Behavior, vol. 27, núm. 3, 2005, pp. 239-260.

IKedA, K., Y. Yamada y M. Kohno, Influence of Social Capital on Political Participation in Asian Cultural Context, Asian Barometer Working Paper Series 10, Taipéi, National Taiwan UniversityAcademia Sinica, 2003.

Kalita, G., "Rural Women's Participation in Electoral Politics", IJCAES Special Issue on Basic, Applied E Social Sciences, vol. 2, 2012, pp. 170-175.

KAZEZ, R., "Los estudios de casos y el problema de la selección de la muestra. Aportes del sistema de matrices de datos", Subjetividad y Procesos Cognitivos, vol. 13, núm. 1, enero-junio de 2009, pp. 71-89.

Klasnja, M. y J. Tucker, "The Economy, Corruption and the Vote: Evidence from Experiments in Sweden and Moldova", Electoral Studies, vol. 32, núm. 3, 2013, pp. 536-543.

Klesner, J., "Social Capital and Political Participation in Latin America. Evidence from Argentina, Chile, Mexico, and Peru", Latin American Research Review, vol. 42, núm. 2, 2007, pp. 1-32. Klesner, J., "Who Participates? Determinants of Political Action in Mexico", Latin American Politics and Society, vol. 51, núm. 2, 2009, pp. 59-90.

Krishna, A., "Enhancing Political Participation in Democracies: What is the Role of Social Capital?", Comparative Political Studies, vol. 35, núm. 4, 2002, pp. 437-460.

Kumar, S. y P. Rai, Measuring Voting Behavior in India, Los Ángeles, Sage Publications, 2013.

LeE, A., "The Quality of Social Capital and Political Participation in South Korea", Journal of East Asian Studies, vol. 10, núm. 3, 2010, pp. 483-505.

Millán, R. y S. Gordon, "Capital social: una lectura de tres perspectivas clásicas”, Revista Mexicana de Sociología, núm. 4, 2004, pp. 711-747.

NaDAL, V., "Participation of Women in Panchayati Raj Institutions: A Sociological Study of Haryana, India", International Research Journal of Social Sciences, vol. 2, núm. 12, 2013, pp. 47-50.

NARAIN, A., "La India trata de resolver el problema de castas por medio del federalismo", Federaciones, vol. 5, núm. 3, 2006, pp. 2324 y 32.

NeETA, L., "Participación política de mujeres a la zaga en India", Inter Press Service Agencia de Noticias, 1 de julio de 2014. [ < http:// $\mathrm{www}$.ipsnoticias.net/2014/07/participacion-politica-de- 
las-mujeres-a-la-zaga-en-india/ > , consultado el 8 de enero de 2016.]

Newton, K., "Political Support: Social Capital, Civil Society and Political and Economic Performance", Political Studies, vol. 54, núm. 4, 2006, pp. 846-864.

Newton, K., "Trust, Social Capital, Civil Society and Democracy”, International Political Science Review, vol. 22, núm. 2, 2001, pp. 201-214.

Nickerson, D., "Is Voting Contagious? Evidence from Two Field Experiments", The American Political Science Review, vol. 102, núm. 1, 2008, pp. 49-57.

Palmer, N., D. Perkins y Q. Xu, "Social Capital and Community Participation among Migrant Workers in China", Journal of Community Psychology, vol. 39, núm. 1, 2011, pp. 89-105.

Portes, A., "Social Capital: Its Origins and Applications in Modern Sociology", Annual Review of Sociology, vol. 24, 1998, pp. 1-24.

Putnam, R., Making Democracy Work. Civic Traditions in Modern Italy, Princeton, Princeton University Press, 1993.

Razafindrakoto, M. y F. Roubaud, Corruption, Institutional Discredit and Exclusion of the Poor: A Poverty Trap, Afrobarometer Working Papers 86, s.1., Michigan State University-Institute for Democracy in South Africa-Centre for Democratic Development, 2007.

Sengupta, J. y S. Debnarayan, "Caste and Religious Diversity on Formation of Social Capital", Equality, Diversity and Inclusion: An International Journal, vol. 31, núm. 2, 2012, pp. 158-175.

SPEHR, S. y N. Dutt, "Exploring Protest Participation in India: Evidence from the 1996 World Values Survey", African and Asian Studies, vol. 3, núm. 3, 2004, pp. 185-218.

Teney, C. y L. Hanquinet, "High Political Participation, High Social Capital? A Relational Analysis of Youth Social Capital and Political Participation”, Social Science Research, vol. 41, núm. 5, 2012, pp. 1213-1226.

Teorell, J., M. Torcal y J. Montero, "Political Participation: Mapping the Terrain", en J. van Deth, J. Montero y A. Westholm (eds.), Citizenship and Involvement in European Democracies: A Comparative Analysis, Londres, Routledge, 2007, pp. 334357.

Tomm, J., "Village and Township Elections in China. Elements of Democratic Governance", A Journal on Politics, vol. 1, núm. 2, 2006, pp. 85-95.

Verba, S., N. Nie y J. Kim, Participation and Political Equality: A 
Seven-Nation Comparison, Cambridge-Nueva York, Cambridge University Press, 1978.

World Values Survey, Wave 5, 2005-2008 Official Aggregate v.20140429. World Values Survey Association, productor asociado: Asep/JDS, Madrid. [<www.worldvaluessurvey.org >, consultado en mayo de 2017.]

World Values Survey, Wave 6, 2010-2014 Official Aggregate v.20140429. World Values Survey Association, productor asociado: Asep/JDS, Madrid. [<www.worldvaluessurvey.org >, consultado en mayo de 2017.]

XINHuA, "Low Political Participation among Chinese", China Daily, 1 de septiembre de 2012. [ $<$ www.chinadaily.com.cn > , consultado el 12 de mayo de 2014.]

Zhang, Y., "Inefficient Public Participation in Politics", Global Times, 7 de agosto de 2013. [<www.globaltimes.cn > , consultado el 12 de mayo de 2014.]

Zhao, L. y X. Yao, "Does Local Social Capital deter Labor Migration? Evidence from Rural China”, documento de trabajo, Center for Labor, Economics and Public Policy Studies, mayo de 2013. [<www.lepp.zju.edu.cn/upload/2013/13053118576110>, consultado el 20 julio de 2014.] 


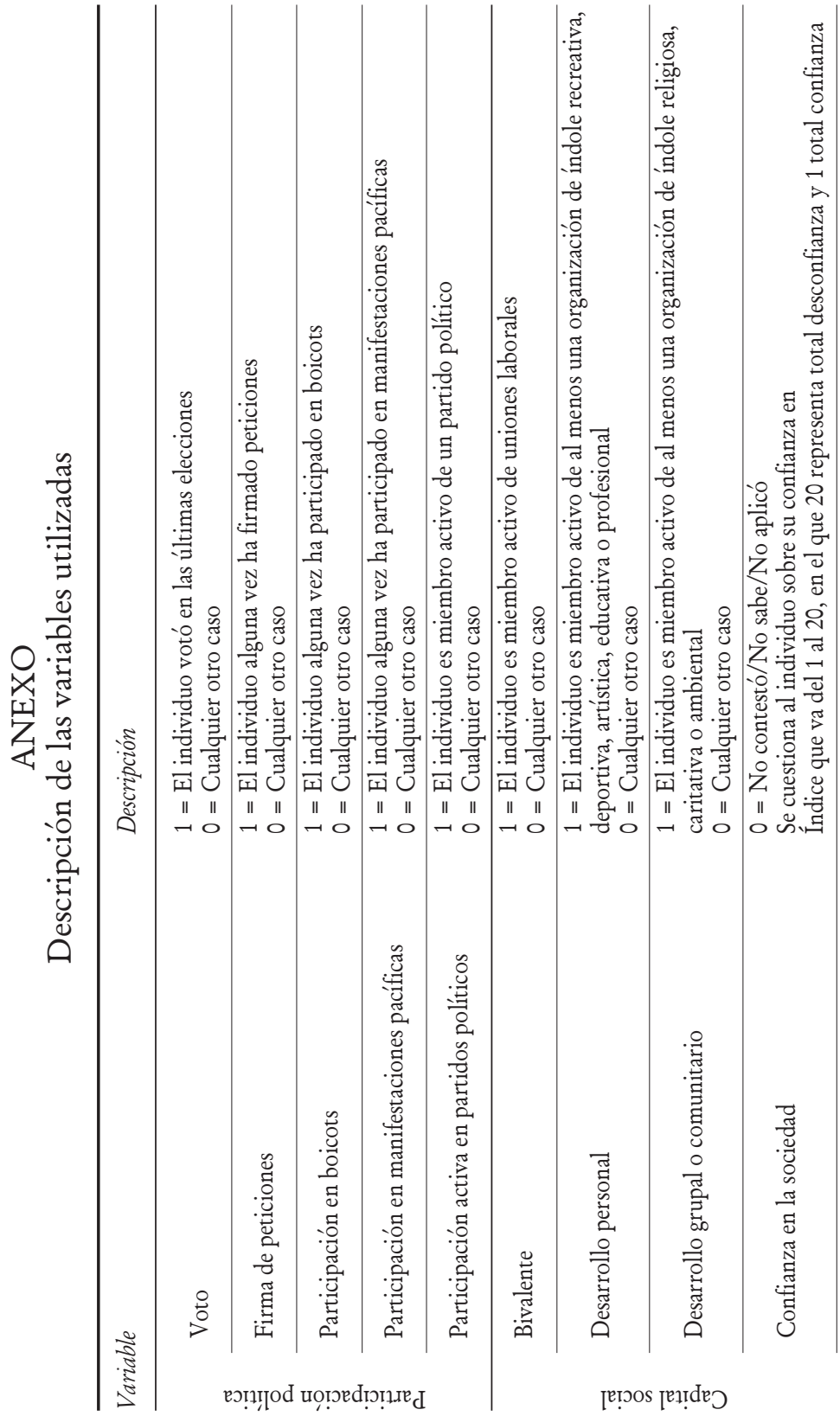


HARO-TAPIA: SOCIEDAD, PARTICIPACIÓN POLÍTICA Y...

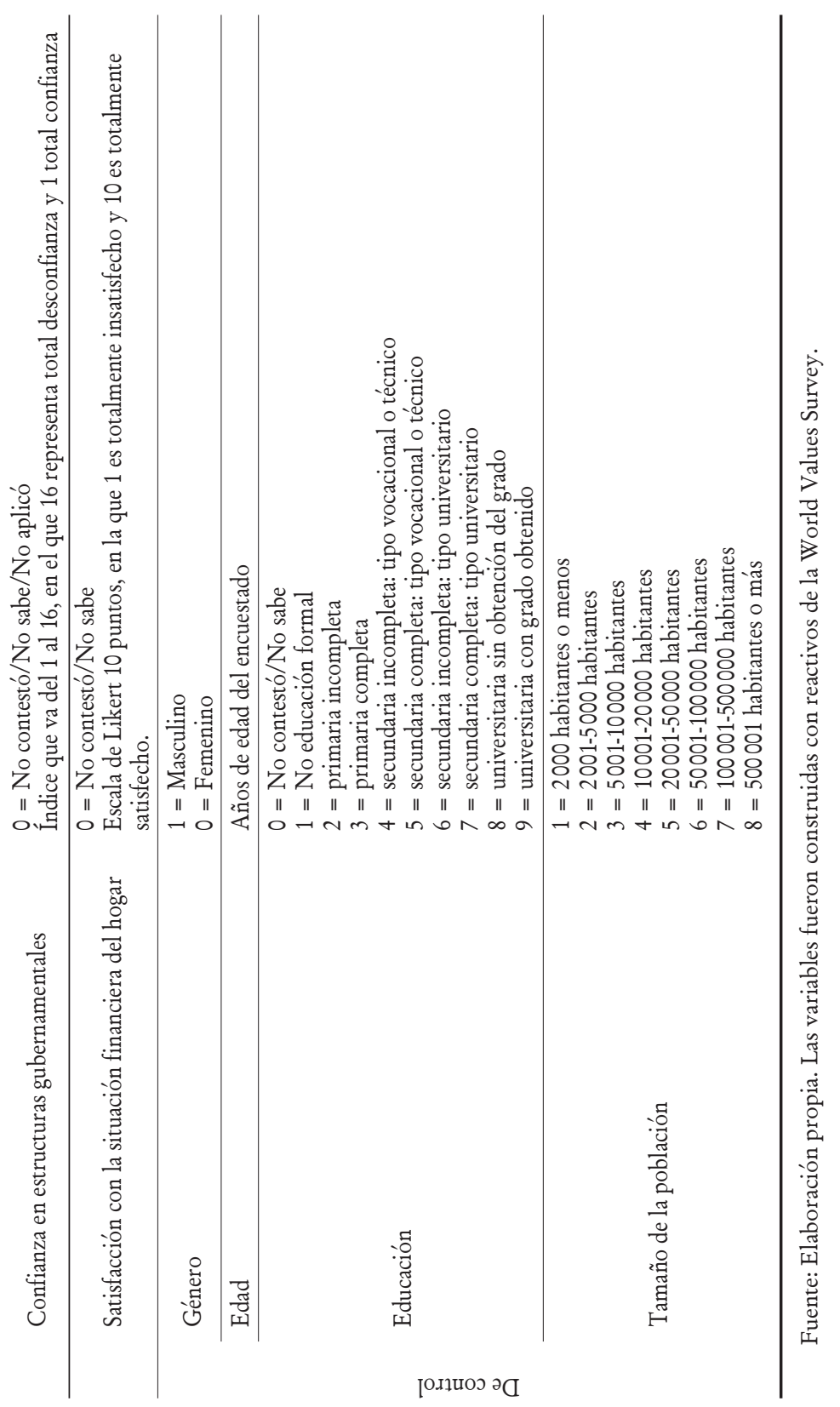


